\title{
Global Launcher Trajectory Optimization for Lunar Base Settlement
}

\author{
Antonio Pagano* and Erwin Mooij ${ }^{\dagger}$ \\ Delft University of Technology, Faculty of Aerospace Engineering, \\ Kluyverweg 1, 2629 HS Delft, The Netherlands
}

\begin{abstract}
The problem of a mission to the Moon to set a permanent outpost can be tackled by dividing the journey into three phases: the Earth ascent, the Earth-Moon transfer and the lunar landing. In this paper we present an optimization analysis of Earth ascent trajectories of existing launch vehicles injected into a Low Earth parking orbit. The trajectories are optimized in the neighborhood of a reference guidance profile. The optimization problem is tackled by using a global method, and a single and multiobjective Particle Swarm Optimization algorithm serve the purpose. The final LEO payload mass is the objective function of the single-objective runs. Path constraints and final orbital elements are used as constraints in the process. However, in the multi-objective optimizations, these constraints are used as objectives together with the payload mass. The launchers' mechanical and thermal constraints, and the launch-sites azimuth constraint are taken into account. It is found that the highest payload masses are achieved by Ariane-5 ESC-A, Atlas V 552 and Proton M, with 25, 24 and 23 tons respectively. Such values, together with the use of all the three launchers and a tight schedule, would permit to build a base in 4.5 years. However, a manned launch vehicle is needed in order to guarantee the assembly and support during the building phase. Also, the dedicated development of a heavy-lift launcher will greatly benefit the moon-base construction.
\end{abstract}

\section{Nomenclature}

Semimajor axis

Axial acceleration

Exit area of the rocket motor

Constraint

Drag coefficient

Lift coefficient

Drag force

Eccentricity

Ellipticity

Force

Earth gravitational acceleration

Earth gravitational acceleration at sea level

Altitude

Inclination

Specific impulse

zonal harmonic coefficient

Lift force

Mach number

Mass

Mass flow $\mathrm{m}$

$\mathrm{m}^{2}$

$\mathrm{m}^{2}$

$\mathrm{N}$

$\mathrm{N}$

$\mathrm{m} / \mathrm{s}^{2}$

$\mathrm{m} / \mathrm{s}^{2}$

$\mathrm{m}$

S

$\mathrm{N}$

$\mathrm{kg}$

$\mathrm{kg} / \mathrm{s}$

*MSc student, celeritas@libero.it

$\dagger$ Assistant Professor, e.mooij@tudelft.nl, Senior Member AIAA. 


$\begin{array}{lll}N_{i n} & \text { Number of bisections of the inner grid } & \\ N_{\text {out }} & \text { Number of bisections of the outer grid } & \mathrm{Pa} \\ p_{a} & \text { Atmospheric pressure } & \mathrm{Pa} \\ q & \text { Dynamic pressure } & \mathrm{W} / \mathrm{m}^{2} \\ \dot{q} & \text { Heat flux } & \mathrm{Pa} \cdot \mathrm{rad} \\ q \alpha & \text { Bending load } & \mathrm{m} \\ r & \text { Radial position of the vehicle } & \mathrm{m} \\ R_{E} & \text { Equatorial radius of the Earth } & \mathrm{m} \\ R_{P} & \text { Polar radius of the Earth } & \mathrm{m} \\ R_{s} & \text { Radius at the surface of the Earth } & \mathrm{m}^{2} \\ S & \text { Reference area of the vehicle } & \mathrm{N} \\ T_{v a c} & \text { Vacuum thrust } & \\ \text { tol } & \text { Orbital element tolerance } & \mathrm{m} / \mathrm{s} \\ v & \text { Velocity of the vehicle } & \mathrm{rad} \\ \alpha & \text { Angle of attack } & \mathrm{rad} \\ \delta & \text { Geocentric latitude } & \\ \delta_{t} & \text { Throttle level } & \mathrm{m}^{3} / \mathrm{s}^{2} \\ \mu & \text { Earth gravitational constant } & \mathrm{kg} / \mathrm{m}^{3} \\ \rho & \text { Atmospheric density } & \mathrm{rad} \\ \psi & \text { Yaw angle } & \end{array}$

Subscripts

$\begin{array}{ll}A & \text { Aerodynamic } \\ G & \text { Gravitational } \\ i & \text { Variable number } \\ I & \text { Inertial planetocentric frame } \\ T & \text { Propulsive } \\ T & \text { Trajectory frame } \\ V & \text { Vertical frame }\end{array}$

Acronyms

$D G-M O P S O$ Double Grid Multi Objective Particle Swarm Optimization

$D S N \quad$ Deep Space Network

LEO Low Earth Orbit

MOPSO Multi Objective Particle Swarm Optimization

PAES Pareto Archived Evolution Strategy

PSO Particle Swarm Optimization

RSS Root Sum Square

\section{Introduction}

In the last years, a renovated spirit for space exploration has arisen and national space agencies have developed different plans in which setting a permanent outpost on the Moon is the first step. ${ }^{1,2}$

To get experience in surviving on planets different from Earth, setting a base on the Moon is the first objective. As such a base should be able to host astronauts, guarantee scientific research and daily activities for the staying duration, some requirements are necessary to make life possible on the lunar surface. Some basic requirements have been selected starting from the ability of the base to host at least 3 astronauts and mobility for the crew of $15 \mathrm{~km}$ around the base. Moreover, a permanent communication link with three ground stations on the Earth separated by $120^{\circ}$ shall be guaranteed. To complete the basic needs, a spaceport to make vehicles land and depart from the base, and a telescope for observation without atmospheric interference are required. All of this has to be in place before July 1, 2020. The aforementioned requirements drove the design of the lunar base to three main sections. The first section is the base itself, that includes four 
inflatable modules with a total mass of 67 tons. This section includes modules and supporting structures, airlocks, hardware and devices for scientific and for life-support purposes. The other two sections are made up by an emergency module and the spaceport (composed of two modules). These two sections, with related structure and airlocks, increase the total mass of the base to 112 tons. In addition, the telescope, communication satellites and a rover bring the total mass to about 120 tons, all of which has to be launched from the Earth. In the beginning, the mission timeline foresees the launch of two communication satellites for a complete coverage of the South Pole. Then, modules and hardware have to be sent requiring the presence of men to assemble them. Eventually, the rover and telescope will be sent. The maintenance of the base starts right after it has been built and supplies need to be delivered regularly.

From a mission-analysis point of view, the mission has been divided into three phases that each component of the base shall go through: Earth ascent, Earth-Moon transfer and lunar landing. Each phase is optimized in order to have the largest payload at the end of the phases themselves. This paper focuses on the first phase, the Earth ascent trajectory. Once all the phases have been analyzed, the payload mass that can be brought to the lunar surface with each launcher is known. However, combining the results obtained from this work with those from the Earth-Moon transfer analysis, a preliminary launch schedule can be sketched.

In the case of ascent trajectories for lunar missions, as the mission is divided into three phases that have to be strictly connected, it is extremely important that the launcher targets for the orbital elements of the selected parking orbit, as these are the initial conditions used for the successive Earth-Moon transfer phase. To better assess this aspect and find at the same time the largest payload mass that can be delivered, a global optimization method is applied to the problem.

Global optimization methods have been widely improved in recent years and have become a quite reliable tool for engineering problems. In the early 1990s, genetic algorithms represented the state of the art even though they exhibited a problem of speed driven by the slow convergence of the solution. Later, many other global methods arose among which Particle Swarm Optimization (PSO) ${ }^{3}$ presented some advantages in terms of convergence speed of the solution. In the past years, this method has grown quite rapidly, reaching the level of genetic algorithms and, sometimes, outperforming them. ${ }^{4}$ The PSO algorithm is based on the collective behavior of a flock of birds looking for food. Based on swarm intelligence, the birds in the flock are assumed to be able to communicate each other the places where food is found, performing optimization.

The PSO method is applied to the ascent trajectory problem. The aim is to find globally optimal trajectories in line with the reference user manuals' payload mass. Eventually, we aim at finding the best strategy and choice of launcher to deliver the payload to the Moon from a logistics point of view.

As the major requirement is the delivery date of the base (i.e., July 1, 2020), a thorough analysis of launchers' capabilities shall be carried out. In this frame, NASA Ares V might give a huge boost in terms of payload delivered on the Moon. However, due to high costs of development, consequent cuts of funding to NASA and the Ares V project being stopped, we decided to rely on existing launchers only. The choice is due to the fact the campaign shall start as soon as possible and it would take time for the development of new launch vehicles. Thus, the launchers analyzed are the most powerful versions of the existing ones: Ariane-5 ESC-A, Delta IV Heavy, Atlas V 552 and HLV, Proton M and Vega.

The layout of this paper is as follows. In Section II the dynamic model used for the ascent problem is illustrated. Section III will discuss the guidance programme used as reference for the ascent trajectories. In Section IV the layout and the model of the PSO algorithm will be presented. Eventually, in Section V results for the first communication mission involving the Vega and cargo mission involving the Ariane-5 ESC-A will be presented. In addition, a preliminary schedule of the launch sequence will be given as well. Section VI, finally, concludes this paper.

\section{Dynamic Model}

\section{A. Equations of motion}

The mathematical model describing the motion of a launcher is simplified by means of a mass-point representation for which a three degrees of freedom analysis will be carried out. The motion of the vehicle will be defined with respect to a rotating, oblate Earth and no wind is assumed. The equations of motion are expressed in an inertial, Earth-centered reference frame: 


$$
\left[\begin{array}{c}
\dot{\vec{V}} \\
\dot{\vec{r}}
\end{array}\right]=\left[\begin{array}{c}
\frac{1}{m}\left(\vec{F}_{A, I}+\vec{F}_{G, I}+\vec{F}_{T, I}\right) \\
\vec{V}
\end{array}\right]
$$

where $\vec{V}$ is the velocity of the launcher with respect to the inertial Earth-centered frame, $\vec{r}$ is the radius vector from the center of the Earth to the vehicle, $m$ is the vehicle's mass and $\vec{F}_{A, I}, \vec{F}_{G, I}$ and $\vec{F}_{T, I}$ refer to the aerodynamic, gravitational and propulsive force, respectively, expressed in the inertial frame. These can be obtained with expressions given in the sub-sections below, and transformed to the inertial frame by standard frame transformations. The Earth is considered to be a rotating, oblate spheroid with a co-rotating atmosphere but otherwise no wind.

\section{B. Aerodynamics}

The aerodynamic force consists of the drag and lift components. The side force has not been considered, because the angle of sideslip has been assumed to be zero, and we are dealing with axisymmetric launch vehicles.

Drag and lift are expressed in the aerodynamic reference frame, but this frame is coincident with the trajectory frame in case no banking flight is considered. For this frame, the $X_{T}$-axis is aligned with the velocity vector, the $Z_{T}$-axis is pointing downward and is contained in the local vertical plane. The $Y_{T}$-axis is contained in the local horizontal plane and completes the right-handed system. These components are defined as:

$$
\vec{F}_{A, A}=\vec{F}_{A, T}\left[\begin{array}{c}
-D \\
0 \\
-L
\end{array}\right]=\left[\begin{array}{c}
-\frac{1}{2} \rho(h) S_{r e f} C_{D}(M, \alpha) V^{2} \\
0 \\
-\frac{1}{2} \rho(h) S_{r e f} C_{L}(M, \alpha) V^{2}
\end{array}\right]
$$

where $\rho$ is the atmospheric density, $S_{\text {ref }}$ is the reference area of the launcher and corresponds to the crosssectional area, $C_{D}$ and $C_{L}$ are the drag and lift coefficients dependent on the Mach number and angle of attack.

The $C_{D}$ and $C_{L}$ coefficients have been obtained respectively from the Ariane- $5 C_{D}$ profile at $0^{\circ}$ angle of attack (from a mission case in the optimization software ASTOS ${ }^{5}$ ) and from Missile DATCOM ${ }^{6}$ respectively. Shortly, the contribution of booster and central core for the Ariane- 5 has been obtained. Then, for each Mach number, an increase per degree has been computed, later averaged over the Mach range from 0.5 to 10 (using as reference Dnepr launcher's $C_{D}$ ). Eventually, the coefficients have been scaled to the launchers' reference areas. Concerning the $C_{L}$ coefficients, data for the central core have been obtained with Missile DATCOM. Then, the contribution of the booster, considered to be the $60 \%$ of that of the core has been added. As this aerodynamic model may be not very precise, in order to assess the capabilities of the software, a $10 \%$ margin has been applied to this so-called "reference" aerodynamic configuration, yielding the so-called "worst" and "best" aerodynamic configurations.

\section{Propulsion}

The thrust can be expressed in the body frame (index B) by the following equation:

$$
\vec{F}_{T, B}(h)=\left[\begin{array}{c}
T_{v a c}-A_{e} \cdot p_{a} \\
0 \\
0
\end{array}\right]
$$

where $T_{v a c}$ is the vacuum thrust, given for each engine from the launcher data, $A_{e}$ is the engine nozzle exit area and $p_{a}$ is the atmospheric pressure. Although this second term is a correction term on the vacuum thrust, it has not been considered in this analysis. As the thrust can be throttled for those engines that make use of it, the propellant mass is computed as:

$$
\dot{m}=\frac{\delta_{T} T_{v a c}}{I_{s p} g_{0}}
$$

where $I_{s p}$ is the specific impulse in the vacuum of the propellant used, $g_{0}$ is the gravity at sea level and $\delta_{T}$ is the throttle level and $\delta_{T} \in[0 ; 1]$ holds. For the vehicle that do not use a throttled thrust, equation (4) is 
used with a fixed throttle level of $\delta_{T}=1$ (e.g., Proton M). In the case of the Ariane-5, the mass flow history for the P230 boosters has been found in literature ${ }^{7}$ and has been used for the thrust computation.

On the other hand, for launch vehicles with throttleable engines or with tailored solid propellant stages, first the throttle level is optimized and then it is multiplied by the vacuum thrust (e.g., Vega, Atlas V, Delta IV). For this kind of engines, the burning phase of each stage is divided by means of nodes. At each node, the throttle level is optimized and the thrust is linearly interpolated between the nodes, creating the thrust profile.

\section{Environment Model}

To obtain results as accurately as possible, the Earth has been considered as an oblate spheroid. Therefore, the radius at the poles and the equator are different, and the surface radius for a particular point on the Earth depends on its geodetic latitude. Since the difference with respect to the geocentric latitude is very small, we can approximate the radius at the surface using the geocentric latitude. Then, the following formula can be applied:

$$
R_{s} \approx R_{E}\left[1-\frac{e}{2}(1-\cos 2 \delta)\right]
$$

where $R_{E}$ is the Earth equatorial radius equal to $6,378.137 \mathrm{~km}, \delta$ is the geocentric latitude and $e$ is the ellipticity of the Earth expressed as:

$$
e=1-\frac{R_{P}}{R_{E}}
$$

The gravitational force is expressed in the Earth-centered rotating frame, and is given by

$$
\vec{F}_{G, R}(h, \delta)=m \vec{g}_{R}
$$

with the gravitational acceleration defined as:

$$
\left.\vec{g}_{R}=\left[\begin{array}{c}
g_{x} \\
g_{y} \\
g_{z}
\end{array}\right]=\left[\begin{array}{c}
-\frac{\mu}{r^{3}} x\left[1+\frac{3}{2} J_{2}\left(\frac{R_{E}}{r}\right)^{2}\left(1-5 \frac{z^{2}}{r^{2}}\right)\right. \\
-\frac{\mu}{r^{3}} y\left[1+\frac{3}{2} J_{2}\left(\frac{R_{E}}{r}\right)^{2}\left(1-5 \frac{z^{2}}{r^{2}}\right)\right. \\
-\frac{\mu}{r^{3}} z\left[1+\frac{3}{2} J_{2}\left(\frac{R_{E}}{r}\right)^{2}\left(3-5 \frac{z^{2}}{r^{2}}\right)\right.
\end{array}\right]\right]
$$

Here, $\mu$ is the Earth gravitational constant equal to $398,600.4415 \cdot 10^{9} \mathrm{~m}^{3} / \mathrm{s}^{2}, r$ is the distance of the launcher from the center of the Earth, $J_{2}$ is zonal-harmonic coefficient related to the Earth's oblateness, and equal to 0.0010826 , and $x, y, z$ are the Cartesian position components of the vehicle in the rotating Earth-centered frame. For the atmosphere, the 1976 US Standard Atmosphere has been considered. ${ }^{8}$

\section{E. Path and boundary constraints}

The launch vehicles are subjected to mechanical and thermal constraints dictated by the characteristics of the structure of each of them. These limits have been taken from the launchers' user manuals or are, in case of the range azimuths, launch-site dependent. The so-called path constraints considered in this analysis are:

- Dynamic pressure, $q$

- Axial acceleration, $a_{x}$

- Peak heat flux, $\dot{q}$

- Bending load, $q \alpha$

- Launch-site azimuth constraints

Concerning the boundary constraints, these are basically the final orbital elements of the LEO parking orbit that the launchers have to reach. When the boundary constraints are specified, also a tolerance for each orbital element is given so that the final orbit is not missed or is not far from the given one. The tolerances have to be fulfilled since the successive phase, the Earth-Moon transfer, starts from pre-specified initial conditions (i.e., the orbital elements of the LEO parking orbit).

The characteristics of the final orbit are given by: 
- Semimajor axis, $a=6563.137 \mathrm{~km}$ (or, equivalently, $h=185 \mathrm{~km}$ )

- Eccentricity, $e=0$

- Inclination, $i=i_{\text {LaunchSite }}$

\section{Reference guidance programme}

In order to reach the final target orbit, any launcher has to follow a given guidance programme. According to the altitude or stage that is active, the guidance law may vary. The discussed guidance is a reference around which the PSO optimizer has to find the optimal profile to be flown by the launcher.

The control angles that determine the trajectory to be flown are the pitch and yaw (roll is not considered as the launchers are considered to be axial-symmetric). These angles describe the launcher's attitude with respect to the local horizontal frame, centered in the vehicle's center of mass, with the $Z_{V}$-axis pointing to the center of the Earth. The $X_{V}$-axis lies in the meridian plane pointing North whereas the $Y_{V}$-axis completes the right-handed system (and is pointing East).

The pitch programme is composed of the following phases:

- Vertical lift-off

- Linear pitch-over

- Exponential decay of the pitch

- Gravity turn (for all stages but the upper one)

- Bi-linear tangent law

- Orbital coast phase (if circularization burn is used)

- Upper stage burn (if circularization is used)

Regarding the yaw, the trajectory is optimized in the neighborhood of a target inclination law expressed as:

$$
\psi=\arcsin \frac{\cos \delta}{\cos i}
$$

where $\delta$ is the latitude of the vehicle, $i$ is the final orbit inclination and $\psi$ is the yaw angle.

The parameters describing the pitch-over maneuver ( $\Delta \theta$ in Eq. 10), the bi-linear tangent law $\left(\theta_{0}, \theta_{f}\right.$ and $\xi \in[-1 ; 1]$ in Eq. 11) and the orbital coast phase (deviation of the true anomaly from $180^{\circ}$, i.e., the apogee of the transfer orbit) are optimized. In addition, for each stage but the upper one, the gravity-turn phase is divided into nodes. At these nodes the optimizer finds the optimal values in a given range around the reference pitch and yaw angles. The same holds for the yaw in the bi-linear tangent phase.

The pitch-over equation is given by:

$$
\left\{\begin{array}{lll}
\theta=\gamma-\frac{t-t_{F 1}}{\Delta t_{T O}} \Delta \theta & \text { for } & t_{F 1}<t<t_{F 1}+\Delta t_{T O} \\
\theta=\gamma-\Delta \theta \exp \left(\frac{-\left(t-t_{T O}\right)}{t_{c}}\right) & \text { for } & t_{F 1}+\Delta t_{T O}<t<t_{F 2}
\end{array}\right.
$$

where $\Delta t_{T O}$ is the duration of the linear pitch over, $t_{c}$ is a parameter of the rotational dynamics of the launcher and $\mathbf{t}_{\mathbf{F} 2}=\mathbf{t}_{\mathbf{F} \mathbf{1}}+\boldsymbol{\Delta} \mathbf{t}_{\mathbf{T O}}+\mathbf{3} \mathbf{t}_{\mathbf{c}}$ is the end of the pitch-over phase. The optimizable variable is given by $\Delta \theta$ and the range in which the optimizer looks for it is $1^{\circ} \leq \Delta \theta \leq 10^{\circ}$.

The bi-linear tangent law is given by:

$$
\tan \theta=\frac{a^{\xi} \tan \theta_{0}+\left(\tan \theta_{f}-a^{\xi} \tan \theta_{0}\right) \hat{t}}{a^{\xi}+\left(1-a^{\xi}\right) \hat{t}} \quad \text { with } \quad \hat{t}=\frac{t-t_{F 4}}{t_{F 5}-t_{F 4}}
$$

where $a>1$ is an arbitrary constant (the larger, the wider the range of values the pitch can assume), $\theta_{0}$ and $\theta_{f}$ are the initial and final values of the pitch angle and $\xi \in[-1 ; 1]$ is a measure of the curvature of $\tan \theta$ profile. 
Besides the aforementioned phases, coasting arcs can also be included between the thrusting phases. In case they are present, the user can specify the lower and upper time durations; then, the optimizer is in charge of finding the optimal values of the arc durations.

\section{PSO algorithm}

The particle swarm optimization method simulates the behaviour of a flock of birds looking for food in a given space. In such a model, each particle has certain characteristics that reflect the optimization variables. Each particle explores the search space and its motion is influenced by the best position where the particle itself found food, and by the absolute best position where food has been found. This model simulates the transmission of information between the particles in the flock and, as a consequence, performs optimization.

\section{A. Single-objective PSO}

The algorithm has been introduced by Kennedy and Eberhart. ${ }^{3}$ Mathematically, the PSO can be described as follows: suppose a solution can be described by a position vector $x_{i}$ (with real-valued elements), then for valid position vectors, a fitness $f_{i}$ can be calculated. Each solution also has an associated velocity vector $v_{i}$ (again, with real-valued elements). The last element of knowledge an individual remembers is the position vector and fitness of the best position it has visited, and a global best position is kept available. At each iteration, the velocity of each individual is determined by the following formula:

$$
v_{i, \text { new }}=w \cdot v_{i}+c_{1} \operatorname{rand}(0,1) \cdot\left(x_{i}^{*}-x_{i}\right)+c_{2} \operatorname{rand}(0,1) \cdot\left(x_{G}^{*}-x_{i}\right)
$$

and the new position is determined using:

$$
x_{i, \text { new }}=x_{i}+v_{i}
$$

in which rand $(0,1)$ is a random number generator with output between 0 and 1 , and $c_{1}$ and $c_{2}$ are constants, called self- and swarm-confidence parameter, (usually with recommended values of $2^{3}$ or $1.494,{ }^{10}$ but it depends on the problem), $x_{i}^{*}$ is the individual's best (archived) position, and $x_{G}^{*}$ is the global best (archived) position.

The single-objective optimizer used for this work implements a linearly decreasing inertia weight, ${ }^{9}$ used in the computation of the particles' velocity, that varies from 0.5 to 0.2 . The self- and swarm-confidence parameters have been set to 1 and 1.5, respectively. The algorithm makes use of a mutation probability feature set to 0.01 . For all the simulations the population size has been set to 100, whereas the number of iterations has been fixed to 100. When optimization is performed through the single-objective PSO optimizer, the path constraints are summed up in a linear penalty function and then multiplied by a weight factor, as:

$$
\text { Penalty }=\left(\sum_{i=1}^{n} \text { ConstraintViolation }_{i}\right) \cdot 10^{10}
$$

where the path constraint violations are computed as:

$$
\text { ConstraintViolation }_{\mathrm{i}}=\left\{\begin{array}{ccc}
0 & \text { if } & x_{i}<C_{i} \\
\frac{\left(x_{i}-C_{i}\right)}{C_{i}} & \text { if } & x_{i}>C_{i}
\end{array}\right.
$$

Then, this penalty function is added to the objective function that, for the single-objective optimization, is the final payload mass.

On the other hand, the boundary constraints, namely the target orbital elements, are summed up into a quadratic penalty function, that is successively added to the objective function (i.e., the final payload mass):

$$
\text { Penalty }=\left(\sum_{i=1}^{n}\left(\frac{x_{i}-x_{T A R G E T, i}}{\operatorname{tol}_{i}}\right)^{2}\right) \cdot 10^{10}
$$




\section{B. Multi-objective PSO}

Concerning the multi-objective optimization, the optimizer used is called Double Grid Multi-Objective PSO (DG-MOPSO), developed by Castellini. ${ }^{11}$ This optimizer is mainly based on the standard MOPSO proposed by Coello Coello, Toscano Pulido and Lechuga ${ }^{12}$ and includes the gridded solution space feature taken from the Pareto Archived Evolution Strategy ${ }^{13,14}$ (PAES).

When more than one objective is subject to optimization, the concept of Pareto dominance is introduced. According to this concept, an optimal solution for a problem consists of all decision variables for which the corresponding objective vector cannot be improved without worsening it in one or more of the other dimensions.

The mentioned grid implemented in DG-MOPSO is a double grid applied to the solution space. This grid is needed to keep trace of the least and the most crowded areas of the objective space. The double grid is structured as follows, see also Fig. 1. The outer grids are divided into inner grids that are meant to move the individuals to the less crowded ones in order to have a uniform distribution of solutions. This is done by assigning, in an outer grid, to each particle a leader positioned in the least crowded inner grid. Once the archive of the best solutions is full, it is pruned by deleting the solutions in the most crowded grids of the objective space.

Also the multi-objective optimizer uses a linearly decreasing inertia weight from 0.5 to 0.2 and a selfand swarm-confidence parameter of 1 and 1.5, respectively. The mutation operator has been set to 0.01 (i.e., $1 \%$ probability). Regarding the configuration of the double grid, the solution space is bisected 4 times (i.e., $N_{\text {out }}=4$ ) and each outer grid is bisected once (i.e., $N_{i n}=1$ ). This setting yields $2^{N_{o u t} \cdot N_{o b j}}$ outer grids and $2^{N_{i n} \cdot N_{o b j}}$ inner grids per outer grid.

As has been said, the constraints used in the single-objective optimization are converted into an objective in the multi-objective one. To do this, we combine the constraints into a single function, the root sum square $(R S S)$, that is minimized together with the payload mass. The $R S S$ of the path constraint is defined as:

$$
R S S_{\text {path_constr }}=\sqrt{\sum_{i=1}^{n} \text { ConstraintViolation }_{i}^{2}}
$$

whereas the $R S S$ of the orbital elements is defined as:

$$
R S S_{\text {orb_elem }}=\sqrt{\sum_{i=1}^{n}\left(\frac{\left(x_{i}-x_{T A R G E T, i}\right)}{\operatorname{tol}_{i}}\right)^{2}}
$$

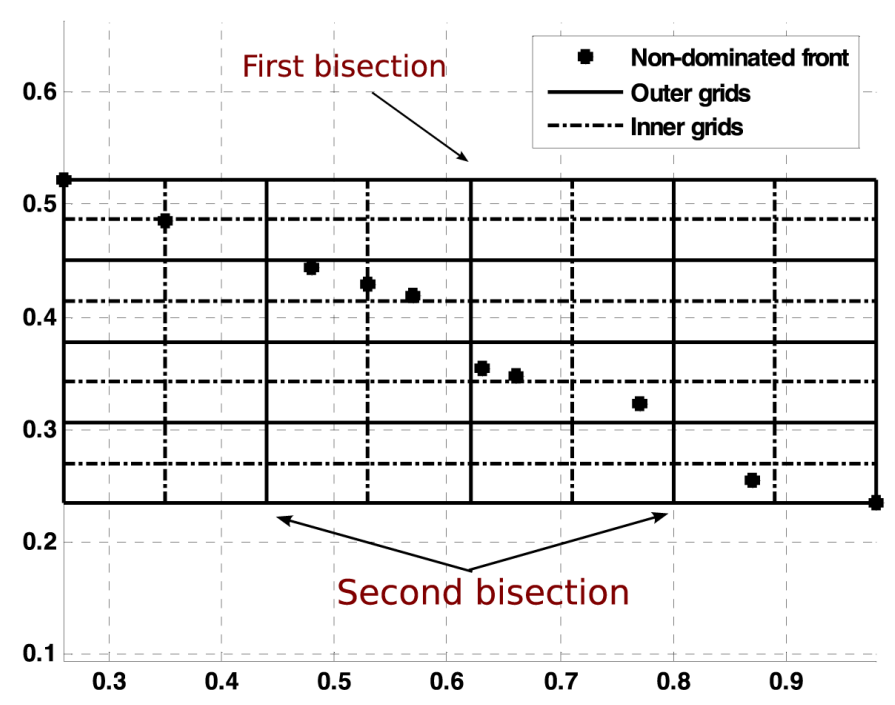

Figure 1. Example of double grid in a (two) objective space. In this case, $N_{\text {out }}=2$ and $N_{\text {in }}=1$. 


\section{Results}

Simulation batches have been executed for the following launchers: Ariane-5 ESC-A, Proton M, Atlas V 552, Delta IV Heavy, Atlas V HLV and Vega. The first five rockets have been analyzed for ascent to a LEO parking orbit, whereas the Vega is supposed to be used for the first mission of the lunar campaign. The first mission foresees the injection of two communication satellites weighing $400 \mathrm{~kg}$ each in a Halo orbit around the Lagrangian point $L_{2}$ of the Earth-Moon system. ${ }^{15}$ The consequent setup permits to have permanent communication between the lunar base and the Deep Space Network (DSN) ground stations. In the EarthMoon transfer phase, the transfer from LEO orbit to the final orbit was analyzed for three different orbit inclinations: $5.5^{\circ}, 28.5^{\circ}$ and $51.6^{\circ}$. Thus, the ascent-trajectory analysis has been performed for the same three final inclinations.

\section{A. Vega \\ 1. One-objective optimization}

The runs performed using one objective only are organized by final orbit inclinations $\left(5.5^{\circ}, 28.5^{\circ}\right.$ and $\left.51.6^{\circ}\right)$. For the orbit inclination in which the largest payload mass is achieved, i.e., $i=28.5^{\circ}$, Table 1 provides the setup of the runs, showing the tolerance set on the orbital elements and the path constraint limits. In addition, in the setup table, the use of the circularization burn and of the coast arcs between the stages is specified. Then, in Table 2, the results are shown. They summarize for each run and for each aerodynamic configuration (worst, reference and best), the error on each orbital-element tolerance. Besides that, if in a particular run the vehicle has violated the constraints, the violation for each constraint is reported. Next, the value reported is the exceeding value with respect to the limit presented in the setup table. Finally, the final payload masses are reported.

\section{Circular orbit@185 km altitude,5.5inclination}

For a final orbit inclination of $5.5^{\circ}$, the payload mass ranges between $2050 \mathrm{~kg}$ and $3600 \mathrm{~kg}$, although most of the runs give a payload mass higher than $2900 \mathrm{~kg}$. Differences between the runs comprise of satisfaction of constraints and accuracy of the orbital elements. However, the tolerance on the final inclination is often not respected, producing errors. In addition, several violations, mostly in the peak heat flux, axial acceleration and geographical constraints are present.

It has to be stressed that the geographical constraint is something related to the launch site's permitted azimuth range and it is active until the rocket reaches $100 \mathrm{~km}$ altitude. This is done to prevent that any jettisoned stage or part of the vehicle will crash on inhabited areas.

The first run is the only one that does not violate any constraints and respects all tolerances. But, the tolerance on the final eccentricity is one order of magnitude higher than all the other cases, showing that the tolerance on this orbital element might have a predominant role in driving the optimization process to a good or bad (in terms of constraints and payload mass) ascent of the launcher. However, even though no constraints or tolerances are violated, the resulting orbit has a pericenter and apocenter that differ by 40 $\mathrm{km}$. This cannot be accepted in LEO since the orbit has to be as circular as possible since the analysis of the Earth-Moon transfer uses this assumption as initial orbit.

When the circularization burn is used to achieve the circular orbit, the tolerance on the eccentricity is not satisfied in the reference aerodynamic configuration and as a consequence it gives a higher payload mass with respect to the other cases.

One curious observation is that most of the runs involving the best aerodynamic configuration tend to violate the bending load, the axial acceleration, the peak heat flux and the dynamic pressure. This behaviour might be explained by considering the velocity of the vehicle. With a better aerodynamic configuration, i.e., lower $C_{D}$ and higher $C_{L}$, the drag experienced by the launcher is lower giving as result a higher velocity that is involved in the dynamic pressure and peak heat flux (and consequently in the bending load). Regarding the axial acceleration, this is simply higher since the drag is lower.

Eventually, it is found that the best aerodynamic configuration does not always produce the highest payload mass. This is due to the fact that path constraints and tolerances are violated more often, resulting in higher penalties in the objective function that might steer the optimization in non-optimal areas of the search space. 
Circular orbit@185 kmaltitude,28.5 inclination

Concerning the orbit with final inclination of $28.5^{\circ}$, as it can immediately be seen in Table 2 , those runs involving the best aerodynamic configuration (all but run 16) violate the tolerance on the final eccentricity. Therefore, all the resulting trajectories cannot be taken into account for the mission, since a strong requirement is satisfying the final orbit characteristics to match the analysis of the Earth-Moon transfer, and to provide a reliable study. In addition, the reason the best aerodynamic configuration behaves so badly with respect to the others has been reported for the $5.5^{\circ}$ orbit-inclination case.

However, going on with the analysis of the table, it results that at this final inclination the azimuthrange constraint is never violated (except in run 1, violated by only $0.25^{\circ}$ ). The first run has the hardest constraints and the vehicle manages to violate the dynamic pressure by only $2 \mathrm{kPa}$ at maximum in the reference configuration. On the other hand, the heat flux is violated by about $70 \mathrm{~kW} / \mathrm{m}^{2}$.

\begin{tabular}{|l|c|c|c|c|c|c|c|}
\hline Parameter & Simulation 7 & Simulation 9 & Simulation 10 & Simulation 11 & Simulation 12 & Simulation 15 & Simulation 16 \\
\hline $\mathrm{a}[\mathrm{km}]$ & 6563.137 & 6563.137 & 6563.137 & 6563.137 & 6563.137 & 6563.137 & 6563.137 \\
\hline $\mathrm{e}[-]$ & 0 & 0 & 0 & 0 & 0 & 0 & 0 \\
\hline $\mathrm{i}[\mathrm{deg}]$ & 28.5 & 28.5 & 28.5 & 28.5 & 28.5 & 28.5 & 28.5 \\
\hline Tolerance a [km] & 2 & 3 & 3 & 3 & 3 & 3 & 3 \\
\hline Tolerance e [-] & 0.0001 & 0.0005 & 0.005 & 0.0005 & 0.0005 & 0.0005 & 0.0005 \\
\hline Tolerance i [deg] & 0.1 & 0.1 & 0.1 & 0.1 & 0.1 & 0.1 & 0.1 \\
\hline $\begin{array}{l}\text { Dynamic } \\
\text { pressure [kPa] }\end{array}$ & $\leq 45$ & $\leq 50$ & $\leq 57$ & $\leq 50$ & $\leq 50$ & $\leq 50$ & $\leq 50$ \\
\hline $\begin{array}{l}\text { Peak heat flux } \\
{\left[\mathrm{kW} / \mathrm{m}^{2}\right]}\end{array}$ & $\leq 100$ & $\leq 120$ & $\leq 180$ & $\leq 120$ & $\leq 120$ & $\leq 160$ & $\leq 120$ \\
\hline $\begin{array}{l}\text { Axial acceleration } \\
{[\mathrm{g}]}\end{array}$ & $\leq 5.5$ & $\leq 5.5$ & $\leq 5.5$ & $\leq 5.5$ & $\leq 5.5$ & $\leq 5.5$ & $\leq 5.5$ \\
\hline $\begin{array}{l}\text { Bending load } \\
{[\mathrm{kPa} \text { deg] }}\end{array}$ & $\leq 200$ & $\leq 280$ & $\leq 300$ & $\leq 300$ & $\leq 300$ & $\leq 300$ & $\leq 300$ \\
\hline $\begin{array}{l}\text { Circularization } \\
\text { burn }\end{array}$ & No & No & No & No & No & No & Yes \\
\hline Coast arcs & No & No & No & No & Yes & No & Yes \\
\hline
\end{tabular}

Table 1. Vega: the setup of the runs, launching into $28.5^{\circ}$ inclination orbit.

Eventually, the best case, run 16, presents no violations for all the configurations. Even though a circularization burn has been included in the setup, the optimal trajectories do not use it. Therefore, this run has the same setup as run 4 but it differs completely in the results. This may be due to the random effect in the initial population, which could cover different areas of the space. Therefore, larger population sizes or multiple runs with different random seeds could be considered as future work.

\begin{tabular}{|c|c|c|c|c|c|c|c|c|}
\hline Parameter & & Simulation 7 & Simulation 9 & Simulation 10 & Simulation 1 & Simulation 12 & Simulation 15 & Simulation 16 \\
\hline \multirow{3}{*}{ Error a } & W & - & - & - & - & - & - & - \\
\hline & $\mathrm{R}$ & - & - & - & - & - & - & - \\
\hline & B & - & - & - & - & - & - & - \\
\hline \multirow{3}{*}{ Error e } & w & - & 0.000542 & - & - & 0.000547 & - & - \\
\hline & $\mathrm{R}$ & & & & - & & 0.000949 & - \\
\hline & B & 0.00015 & 0.000735 & 0.000545 & 0.000649 & 0.000531 & 0.000727 & - \\
\hline \multirow{3}{*}{ Error $\mathrm{i}$} & W & - & - & - & - & $0.40 \%$ & - & - \\
\hline & $\mathrm{R}$ & - & - & - & - & - & - & - \\
\hline & B & $3.32 \%$ & - & $0.86 \%$ & - & - & & - \\
\hline \multirow{3}{*}{\begin{tabular}{|l|} 
Dynamic \\
pressure \\
violation $[\mathrm{kPa}]$
\end{tabular}} & $w$ & 1.3 & - & - & - & - & 0.9 & - \\
\hline & $\mathrm{R}$ & 2.7 & - & - & - & - & - & - \\
\hline & B & 0.9 & - & - & 13.0 & - & - & - \\
\hline \multirow{3}{*}{$\begin{array}{l}\begin{array}{l}\text { Peak heat flux } \\
\text { violation } \\
{[\mathrm{kW} / \mathrm{m} 2]}\end{array} \\
\end{array}$} & W & 73.4 & - & - & 25.6 & - & - & - \\
\hline & $\mathrm{R}$ & - & 37.0 & 46.7 & 30.8 & 99.1 & - & - \\
\hline & B & 76.5 & - & - & 58.6 & 136.9 & - & - \\
\hline \multirow{3}{*}{$\begin{array}{l}\text { Axial } \\
\text { acceleration } \\
\text { violation }[\mathrm{g}]\end{array}$} & w & 0.9 & - & - & 0.9 & 0.0 & 0.5 & - \\
\hline & $\mathrm{R}$ & - & - & - & - & - & - & - \\
\hline & $B$ & - & 0.2 & - & 1.2 & - & - & - \\
\hline \multirow{3}{*}{$\begin{array}{l}\text { Bending moment } \\
\text { violation } \\
{[\mathrm{KPa} * \text { deg }]}\end{array}$} & w & 133.8 & - & - & - & - & 27.7 & - \\
\hline & $\mathrm{R}$ & - & - & - & 8.4 & - & 227.0 & - \\
\hline & B & - & - & - & 265.3 & - & - & - \\
\hline \multirow{3}{*}{$\begin{array}{l}\text { Geographical } \\
\text { violation [deg] }\end{array}$} & $\mathrm{W}$ & . & - & - & - & - & - & - \\
\hline & $\mathrm{R}$ & 0.3 & - & - & - & - & - & - \\
\hline & B & - & - & - & - & - & - & - \\
\hline \multirow{3}{*}{$\begin{array}{l}\text { Final payload } \\
\text { mass }[\mathrm{kg}]\end{array}$} & w & 3,322 & 3,281 & 3,475 & 3,393 & 3,141 & 3,295 & 3,264 \\
\hline & $R$ & 2,802 & 3,099 & 3,186 & 3,441 & 3,489 & 2,811 & 3,312 \\
\hline & B & 3,326 & 3,052 & 3,225 & 3,238 & 3,098 & 2,954 & 2,881 \\
\hline
\end{tabular}

Table 2. Vega: a summary of the optimization runs is presented. The error on the final orbital elements are shown. Final orbit inclination is $28.5^{\circ}$. 
The results achieved for trajectories with $51.6^{\circ}$ as final orbit inclination are presented here. In the case of orbits with $51.6^{\circ}$ as final inclination only two runs have been performed. Both the trajectories include the option for coast arcs, but only one of them includes the option for the circularization burn. However, also in this case the flown trajectories do not make use of it. In this sense, again the main differences between the two cases can be due to the fact that the initial populations randomly created by the optimizer, cover different areas of the search space.

However, by comparing the final mass of the different aerodynamic configurations, it can be noticed that there is no clear relation between the aerodynamics and the final payload mass. For instance, the values in the worst configuration are higher than those in the reference one. This is a very strange result and it might only be addressed to the fact the same random seed was not used for the same simulation because of errors arisen during the integration for certain configurations (the error was not dependent on a certain configuration). Therefore, the variation of obtained masses has to be accounted for by the different initial populations. In addition, concerning the orbital elements and the path constraints, the violations occur only in the worst and reference configurations.

In the first of these two runs, the errors on the final orbital elements point out that the found control profile is not the optimum for both yaw and pitch. This results in an error in the final inclination, mainly due to the yaw profile, and an error in the final eccentricity due to the pitch profile. The violations in the axial acceleration indicate that, depending on the initial populations, the optimal values at the nodes for the throttle setting were not always found. The solution might be either to have simulations with lower minimum throttle level or with the real thrust profile of the stages (since they are solid-propellant fueled and with a tailored thrust). On the other hand, the violation of the peak heat flux and of the bending load is due to the longer time spent in the atmosphere. This is due to the fact that the launcher arrives at a wrong orbit with a lower altitude.

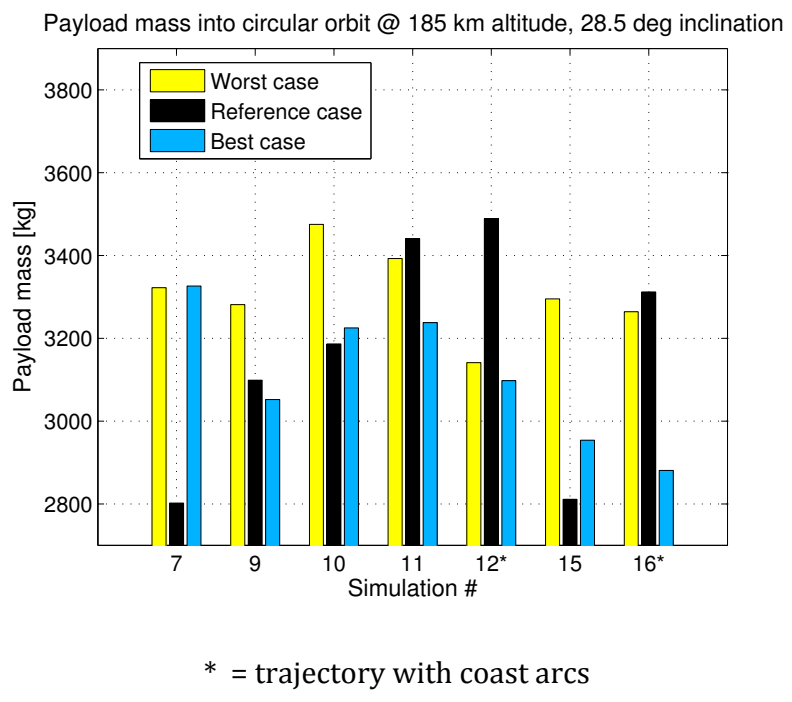

Figure 2. Final payload mass at $28.5^{\circ}$ inclination.

Fig. 2 shows that in some simulations one of the configurations has a payload mass much smaller than the other two. In some cases, as run 7, one aerodynamic configuration has small violations compared to the other two. This is due to the fact that the optimizer is able to find a solution with a smaller payload that does not violate the constraints. In other cases, e.g., run 15, the found solution is not optimal and large constraint violations occur, whereas in the optimal solutions there are no violations. 


\section{Trajectory accuracy}

\section{Semimajor axis accuracy}

The only cases in which the semimajor axis tolerance is violated are run 13 and 18, in the reference aerodynamic configuration. It can be seen that in both cases together with this violation also the other two orbital-element tolerances are not satisfied. This might be due to the fact that, while trying to reach the tolerance set on the eccentricity, there is a point at which the set semimajor axis tolerance is satisfied, but not the one of eccentricity. Then the vehicle keeps flying, in order to satisfy the eccentricity tolerance, but then the semimajor axis is already out of its bounds. At this point the trajectory simulation is stopped giving an error on both elements. Of course this explanation has also to take into account that the optimizable parameters might not be the optimal ones.

The problem about the optimizer not finding the optimal control angles depends on the initial population. If the particles flying in the search space are "stuck" in areas where violations of constraints occur, as the optimization goes on, this situation cannot change because the linearly decreasing inertia weight makes the search more exploitative than explorative.
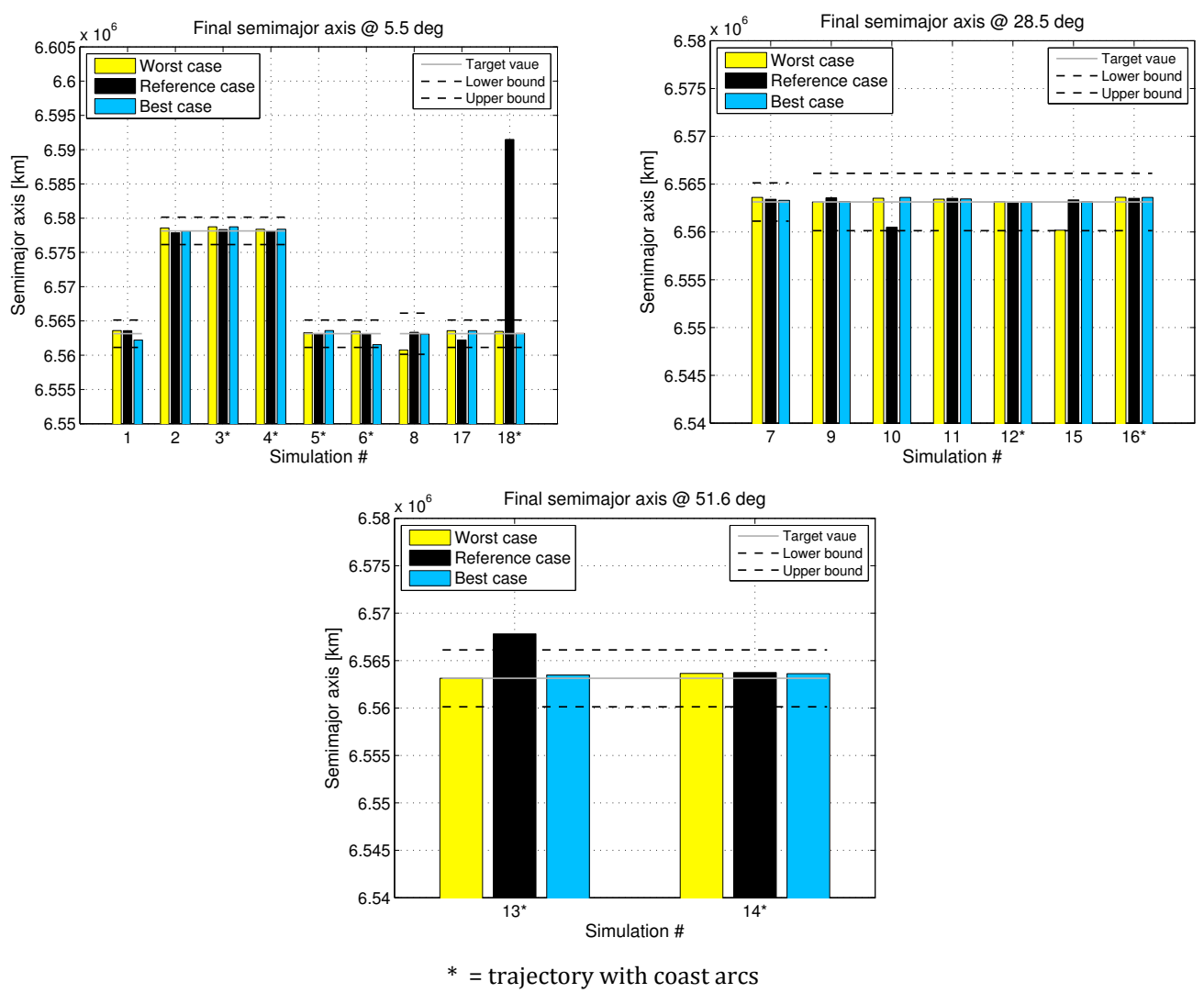

Figure 3. Vega: the best semimajor axis accuracies have been achieved for the $28.5^{\circ}$ orbit inclination. The solid grey line indicates the target orbital element and the dashed black one indicates the boundaries given by the tolerances around the target value.

\section{Eccentricity accuracy}

The tolerance on the eccentricity is the most violated amongst the orbital elements because a circular orbit is difficult to achieve with a direct launch. Moreover, the violations occur in those trajectories, which tolerance is 0.0001 or for vehicles with the best configuration. The reason may be that having a higher velocity (due to lower drag, with the best configuration), the launcher reaches about $170 \mathrm{~km}$ in a shorter time and has less time to curve towards a circular orbit, at $185 \mathrm{~km}$. In this way it misses slightly (or heavily in some cases) the set tolerance. A drawback of this trajectory is that, by spending a longer time in the denser layers of 
the atmosphere, the vehicle violates slightly the dynamic pressure, the bending load and the peak heat flux.

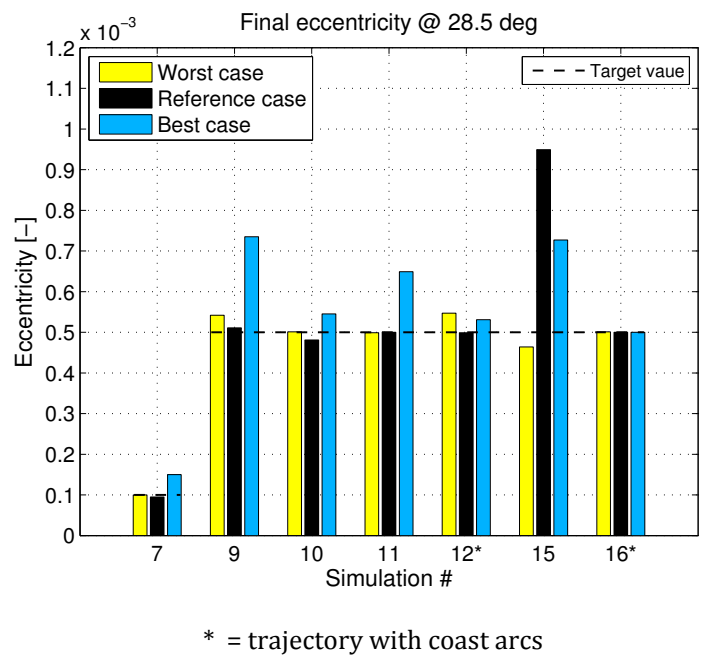

Figure 4. Vega: eccentricity accuracies achieved for the $28.5^{\circ}$ orbit inclination. Since the target value is 0 for a circular orbit, there is no lower bound as a negative eccentricity does not exist.

\section{Inclination accuracy}

Fig. 5 shows the final inclination reached by several runs. It might be strange that an orbit with a lower inclination than the launch site latitude can be reached. This is formulated from the following geometric formula:

$$
\cos i=\frac{\cos \delta_{0}}{\sin \psi_{0}}
$$

where $i$ is the inclination of the orbit, $\delta_{0}$ is the latitude of the launch site and $\psi_{0}$ is the launch azimuth (or heading angle). From here, we can derive that the minimum inclination that can be reached from a launch site is by launching with $\psi_{0}=90^{\circ}$ (due east) for which an inclination equal to the latitude of the launch site is achieved.

However, the lower inclinations reached in some cases (as in run 7 which can be seen in Fig. 5) are possible because during the trajectories there are several plane changes achieved by means of attitude control. The yaw angle is mainly responsible for this event that steers the launcher towards the desired inclined plane. Of course, this plane change has some cost in terms of propellant that penalizes the final payload mass.

\section{3. $\quad$ Path constraints}

From the analysis of data concerning the path constraints it is possible to appreciate which mechanical and thermal properties have a major influence on the behavior of the trajectory.

For Vega as well as for other launchers, the peak heat-flux limit is not known and neither is the bendingload limit. Therefore from the assumed limits, the major violations occur in the bending load and peak heat flux. These two characteristics are very important during the ascent and they should be satisfied as much as possible. Moreover, the fact that the bending load is often violated is due to the fact the angle of attack can get to $10^{\circ}$ quite easily. Normally, during flown trajectories it is kept below this value, and if possible below $5^{\circ}$.

Furthermore, this analysis shows that the optimizer is not able to find control parameters at the nodes that result in lower angles of attack. However, to solve this issue, in future research the effect of a constraint on the angle of attack should be investigated. Actually, only a constraint on the dynamic pressure and the bending load is present, and a constraint on the angle of attack might also help to better satisfy the bending load. 


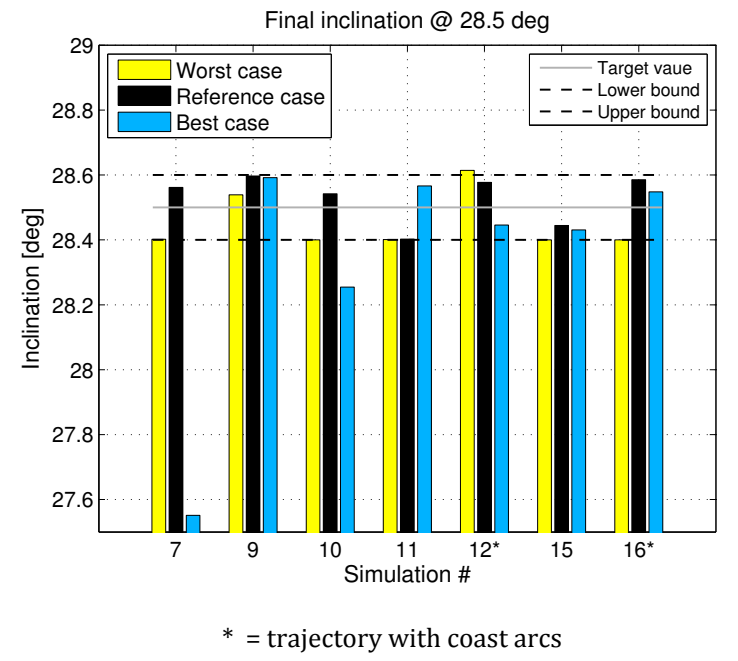

Figure 5. Vega: best inclination accuracies have been reached for $28.5^{\circ}$ orbit inclination.

\section{Two-objectives optimization results}

Regarding the two-objective optimization, 4 runs have been performed for Vega. Table 3 shows the final orbital elements, relative tolerances and constraint limit sets.

In this kind of optimization, there is one run for each final inclination, except for a $28.5^{\circ}$ inclination for which two runs have been performed.

Table 3. Vega: two-objectives optimization settings: final orbital elements and constraint limits.

\begin{tabular}{|l|c|c|c|c|}
\hline Parameter & Simulation 1 & Simulation 2 & Simulation 3 & Simulation 4 \\
\hline $\mathrm{a}[\mathrm{km}]$ & 6563.137 & 6563.137 & 6563.137 & 6563.137 \\
\hline $\mathrm{e}[-]$ & 0 & 0 & 0 & 0 \\
\hline $\mathrm{i}[\mathrm{deg}]$ & 5.5 & 28.5 & 28.5 & 51.6 \\
\hline Tolerance a [km] & 3 & 3 & 3 & 3 \\
\hline Tolerance e [-] & 0.0005 & 0.0005 & 0.0005 & 0.0005 \\
\hline Tolerance $\mathrm{i}[\mathrm{deg}]$ & 0.1 & 0.1 & 0.1 & 0.1 \\
\hline $\begin{array}{l}\text { Dynamic } \\
\text { pressure }[\mathrm{kPa}]\end{array}$ & $\leq 50$ & $\leq 50$ & $\leq 50$ & $\leq 50$ \\
\hline $\begin{array}{l}\text { Peak heat flux } \\
{\left[\mathrm{kW} / \mathrm{m}^{2}\right]}\end{array}$ & $\leq 120$ & $\leq 120$ & $\leq 120$ & $\leq 160$ \\
\hline $\begin{array}{l}\text { Axial acceleration } \\
{[\mathrm{g}]}\end{array}$ & $\leq 5.5$ & $\leq 5.5$ & $\leq 5.5$ & $\leq 5.5$ \\
\hline $\begin{array}{l}\text { Bending load } \\
{[\mathrm{kPa} \text { *deg] }}\end{array}$ & $\leq 300$ & $\leq 280$ & $\leq 280$ & $\leq 300$ \\
\hline $\begin{array}{l}\text { Circularization } \\
\text { burn }\end{array}$ & No & No & No & Yes \\
\hline Coast arcs & No & No & Yes & No \\
\hline
\end{tabular}

The main difference between the four runs is in the bending load limit and in the peak heat flux that is higher for the trajectory reaching $51.6^{\circ}$. In addition, for this final condition, the circularization burn may be used if necessary.

The first thing to say about this multi-objective optimization is that the $R S S$ of the final orbital elements is a measure of the accuracy achieved in the trajectory. If the $R S S$ is smaller than $1(R S S<1)$, it means that the final orbital elements of the relative trajectory satisfy all the tolerances set.

In the analysis of the Pareto front obtained by the four runs the attention shall be focused on those trajectories that present a $R S S \leq 1$ or, if none, as closely to 1 as possible. The reason for this choice is that a LEO parking orbit is a low orbit for which apocentre and pericentre might decrease quite rapidly due to atmospheric drag. Furthermore, the highest accuracy has to be striven in order to match the initial condition of the next Earth-Moon transfer phase.

However, concerning the orbital elements, this assumption does not exclude that a trajectory with a $R S S>1$ might still satisfy all the tolerances. This is because each single term in the $R S S$ formula (see 
Eq. 18) represents the measure of satisfaction of the single tolerance. Each single term can be still lower than 1 but when they are added together, their sum can get up to 3 (in case semimajor axis, eccentricity and inclination tolerances only are considered). By taking the root square of the term we have a maximum value of 1.73 . Therefore, if we say that the $R S S$ has to be smaller than 1 , we are assuming that the point in space that represents the target orbital elements (three in this very case) has a spherical space around it in which the actual trajectory can satisfy all the tolerances.

On the other hand, if we consider that the $R S S$ has to be smaller than 1.73, we are considering a cubic space around the target point. The spherical space tells us that the tolerances are satisfied for sure, whereas the cubic space does not imply that all the tolerances are satisfied, but there could be at least two that might violate them.

A solution to this problem has not been found and the disadvantage of the $R S S$ appears. The only thing that can be done would be the use of a flag for each tolerance, which records if the single orbital element is smaller or larger than 1 . In this way the user has an insight, when looking at the $R S S$, on whether tolerance violations occur at all. What has been said so far does not apply to the $R S S$ of the path constraints, since the formula used for this case is different from the one used for the orbital elements. The trajectories with an $R S S$ following the aforementioned requirements are listed in Table 4.

Table 4. Vega: payload masses for the best trajectories resulting from the two-objective optimizations. The green cells highlight the trajectories that satisfy the given tolerances on the final orbital elements according the criterion $R S S<1$.

\begin{tabular}{|c|c|c|c|c|c|c|c|c|}
\hline & \multicolumn{2}{|c|}{ Run 1} & \multicolumn{2}{|c|}{ Run 2} & \multicolumn{2}{|c|}{ Run 3} & \multicolumn{2}{|c|}{ Run 4} \\
\hline & $\begin{array}{c}\text { Payload mass } \\
{[\mathrm{kg}]}\end{array}$ & $\begin{array}{l}\text { RSS orbital } \\
\text { elements }\end{array}$ & $\begin{array}{c}\text { Payload mass } \\
{[\mathrm{kg}]}\end{array}$ & $\begin{array}{c}\text { RSS orbital } \\
\text { elements }\end{array}$ & $\begin{array}{c}\text { Payload mass } \\
{[\mathrm{kg}]}\end{array}$ & $\begin{array}{c}\text { RSS orbital } \\
\text { elements }\end{array}$ & $\begin{array}{c}\text { Payload mass } \\
{[\mathrm{kg}]}\end{array}$ & $\begin{array}{l}\text { RSS orbital } \\
\text { elements }\end{array}$ \\
\hline \multirow{3}{*}{ Worst } & 3,441 & 1.077 & 3,268 & 0.9695 & 3,307 & 0.9352 & 3,169 & 1.229 \\
\hline & 3,454 & 1.082 & 3,269 & 0.9977 & 3,402 & 1.069 & 3,173 & 1.549 \\
\hline & 3,522 & 1.269 & & & 3,404 & 1.078 & & \\
\hline \multirow{2}{*}{ Reference } & $3,282.50$ & 2.763 & 3,419 & 2.006 & 3,447 & 1.801 & 3,034 & 1.674 \\
\hline & $32,832.80$ & 2.789 & 3,421 & 2.172 & 3,453 & 2,325 & 3,043 & 1.994 \\
\hline \multirow{4}{*}{ Best } & 3,391 & 0.8965 & 2,607 & 2.58 & 3,484 & 1.882 & 3,263 & 1.066 \\
\hline & 3,392 & 0.9345 & 2,609 & 2.609 & 3,491 & 3.291 & 3,269 & 1.235 \\
\hline & $\begin{array}{l}3,393 \\
3,3\end{array}$ & 0.9725 & & & & & & \\
\hline & 3,405 & 0.9942 & & & & & & \\
\hline
\end{tabular}

It must be said that the trajectories present in Table 4 do not violate the path constraints (dynamic pressure, peak heat flux, bending moment and axial acceleration) at all. Moreover, trajectories reaching $5^{\circ}$ inclination orbits yield a maximum payload mass of $3,405 \mathrm{~kg}$ that is quite close to the highest value achieved in the single-objective optimization.

From the closest view of Fig. 6(a), it results that the trajectories with an $R S S$ following the aforementioned requirements are listed in Table 4.

\section{Three-objectives optimization results}

Regarding the three-objective optimization, 2 runs have been performed. Table 5 shows the final orbital elements, relative tolerances and constraint limits set.

In the first run, most of the found solutions have an $R S S$ of the path constraints close to 0 . It is clear that all the solutions of the Pareto surface can be used according one's criteria of design of the mission. If final orbit element did not have to be satisfied with high accuracy and slight violations in the path constraints were permitted, then a solution giving a higher payload mass would be available. This kind of analysis is very useful especially when no maiden flight has occurred yet and the effects that might derive from it are investigated.

In this multi-objective optimization, for run 2, the $R S S$ of two groups of path constraints has been included in the simulation. In this case the orbital elements are used as constraints. The first group of constraints is composed by dynamic pressure and axial acceleration constraints. The second group is made by peak heat flux, bending load and geographical constraints. The objectives are the RSS of the constraints themselves. Moreover, one has to be careful to create the groups by balancing the type of constraints included, e.g., by splitting the dynamic pressure and bending load. This trick should give a balance in the importance of the constraints as the bending load is composed by the dynamic pressure term. Therefore, if a violation occurs in the dynamic pressure, it might also occur in the bending load and vice versa. 


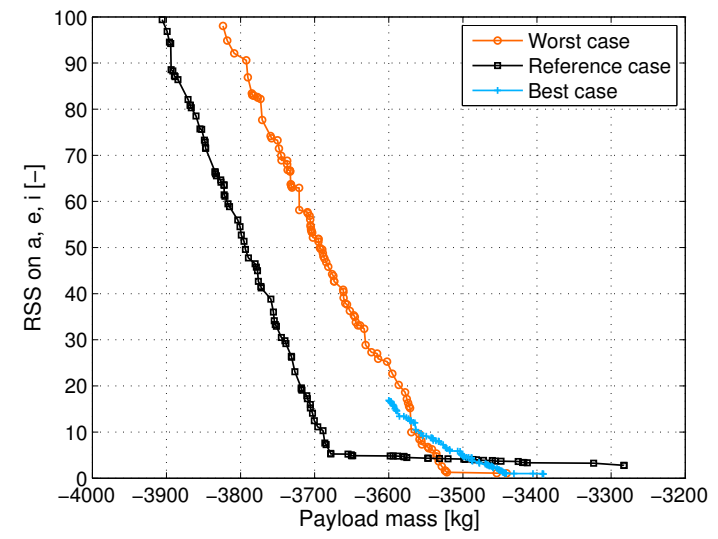

(a) Run 1. Final orbit inclination is $5.5^{\circ}$. It might be apparent that, for the best aerodynamic configuration, the particles found by the optimizer are less than the other two case. This is not the case but it is due to the fact that all the solutions composing the Pareto (that are as many as in the other cases) have a RSS lower than 20 .

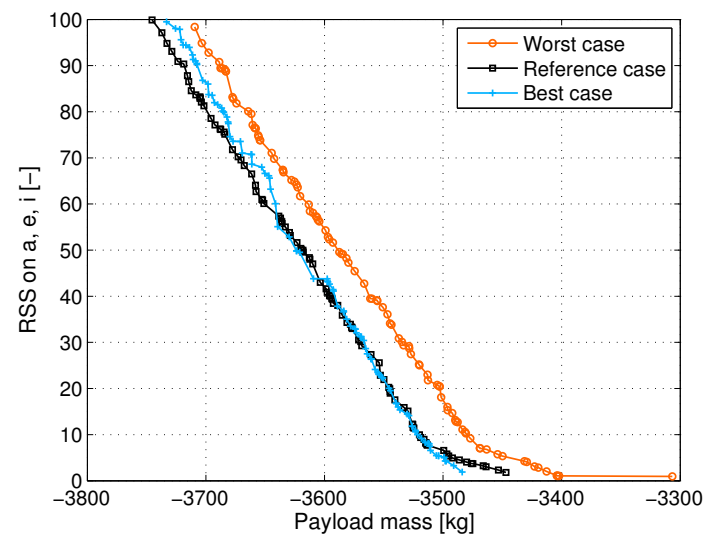

(c) Run 3. Final orbit inclination $28.5^{\circ}$.

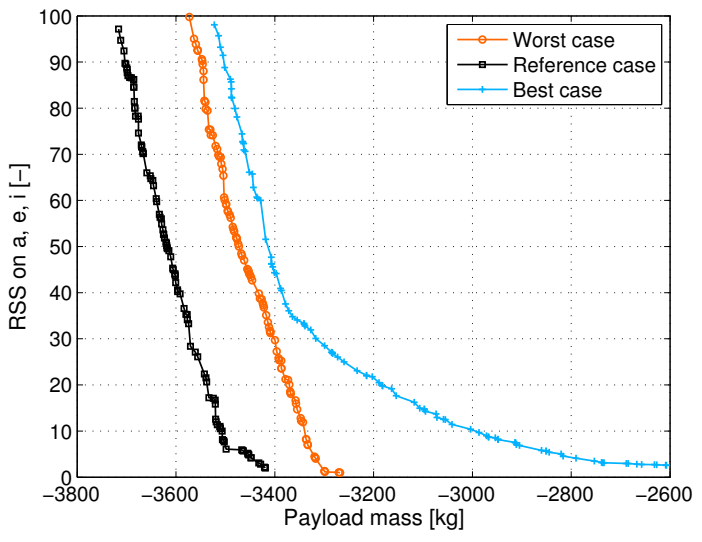

(b) Run 2. Final orbit inclination $28.5^{\circ}$.

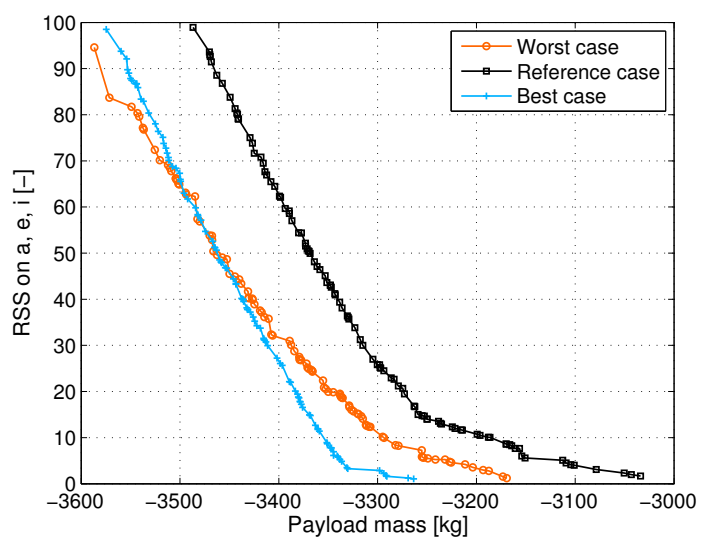

(d) Run 4. Final orbit inclination $51.6^{\circ}$.

Figure 6. Vega: Pareto fronts for two-objective optimization results.

The meaning of a $R S S$ of the path constraints is not the same as in the case of the orbital elements. In this case the RSS gives a measure of the total violation of the constraints. Solutions with a higher $R S S$ of the path constraints of the first group have a lower $R S S$ of path constraints of the second group (which is the criterion of Pareto dominance to find the solutions on the Pareto surface). It is also apparent that solutions of the reference aerodynamic case have a much higher $R S S$ along both groups and a lower payload mass, that means the optimizer completely missed the right area where better solutions were (that might be addressed to the initial population).

Moreover, by using this type of objective, it is more likely that trajectories with constraint violations will result in order to form the Pareto surface. If a trajectory, where no violations occur, is found the whole Pareto surface would reduce to one point (if no other trajectories without violations are found). This would be a good trajectory for the launcher but would alter the purpose of the multi-objective optimization.

Eventually, from Table 6, applying the criterion for which a trajectory is selected if it satisfies the constraints, we can apply a second criterion according to which the trajectory has to satisfy the tolerances on the orbital elements. Therefore, in this case, the optimal solution is given by the highlighted green cells, yielding a final payload mass of $3,046 \mathrm{~kg}$.

On the other hand, for run 2, none of the depicted trajectories can be selected since they all violate at least one group of constraints. 
Table 5. Vega: three-objectives optimization settings: final orbital elements and constraints limits.

\begin{tabular}{|l|c|c|}
\hline Parameter & Simulation 1 & Simulation 2 \\
\hline $\mathrm{a}[\mathrm{km}]$ & 6563.137 & 6563.137 \\
\hline $\mathrm{e}[-]$ & 0 & 0 \\
\hline $\mathrm{i}[\mathrm{deg}]$ & 5.5 & 5.5 \\
\hline Tolerance $\mathrm{a}[\mathrm{km}]$ & 3 & 3 \\
\hline Tolerance e $[-]$ & 0.0005 & 0.0005 \\
\hline Tolerance $\mathrm{i}[\mathrm{deg}]$ & 0.1 & 0.1 \\
\hline $\begin{array}{l}\text { Dynamic pressure } \\
{[\mathrm{kPa}]}\end{array}$ & $\leq 50$ & $\leq 50$ \\
\hline $\begin{array}{l}\text { Peak heat flux } \\
{\left[\mathrm{kW} / \mathrm{m}^{2}\right]}\end{array}$ & $\leq 120$ & $\leq 120$ \\
\hline $\begin{array}{l}\text { Axial acceleration } \\
{[\mathrm{g}]}\end{array}$ & $\leq 5.5$ & $\leq 5.5$ \\
\hline $\begin{array}{l}\text { Bending load } \\
{[\mathrm{kPa} \text { *deg] }}\end{array}$ & $\leq 300$ & $\leq 300$ \\
\hline $\begin{array}{l}\text { Circularization } \\
\text { burn }\end{array}$ & Yes & Yes \\
\hline Coast arcs & Yes & Yes \\
\hline
\end{tabular}

Table 6. Vega: three-objective optimization. In run 1, only the best aerodynamic configuration manages to have a $R S S<1$. Run 2 does not give any flyable trajectory.

\begin{tabular}{|c|c|c|c|c|c|c|}
\hline & \multicolumn{3}{|c|}{ Run 1 } & \multicolumn{3}{c|}{ Run 2 } \\
\hline & $\begin{array}{c}\text { Payload } \\
\text { mass [kg] }\end{array}$ & $\begin{array}{c}\text { RSS path } \\
\text { constraints }\end{array}$ & $\begin{array}{c}\text { RSS orbital } \\
\text { elements }\end{array}$ & $\begin{array}{c}\text { Payload } \\
\text { mass [kg] }\end{array}$ & $\begin{array}{c}\text { RSS path } \\
\text { constraints } \\
\text { (group 1) }\end{array}$ & $\begin{array}{c}\text { RSS path } \\
\text { constraints } \\
\text { (group 2) }\end{array}$ \\
\hline \multirow{2}{*}{ Worst } & 3,666 & 6.4 & 2.9 & 3,190 & 0.095 & 0 \\
& 3,706 & 3.628 & 2.989 & 3,188 & 0.0744 & 0.00046 \\
\cline { 2 - 7 } Reference & 3,502 & 0.211 & 8.019 & 1,795 & 73.48 & 10.7 \\
\hline \multirow{2}{*}{ Best } & 3,046 & 0 & 0.985 & 3,624 & 0.0279 & 0.591 \\
& & & & 3,623 & 0.025 & 0.595 \\
\hline
\end{tabular}

$=$ trajectory without path constraint

and orbital element tolerance violations

\section{Conclusions}

In conclusion, for Vega, all the found optimal trajectories do not make use of any orbital coast phase, even though the option of circularization is available. The launcher burns its stages till reaching the final orbit because the burnout of the stage before the upper one occurs at about $160 \mathrm{~km}$ altitude. At that altitude it is not convenient to use a coast phase anymore since the final orbit is $25 \mathrm{~km}$ higher.

Moreover, the coast arcs between the stages, when active, are in the 2-8 seconds range. However, no advantages seem to come from the use of coasting periods for the configuration and the trajectories flown by this launcher.

In Fig. 7(a), the control history for the best solution is presented, where the nodes can be clearly seen during the gravity turn (pitch and yaw) and the bi-linear tangent law (yaw). The profile refers to the solutions found in run 10 in the worst aerodynamic configuration that yields a final payload mass of 3,475 $\mathrm{kg}$. Still, the yaw presents some sharp changes in the control profile and it has to be verified if the vehicle can fly this kind of profile. In Fig. 7(b), the altitude-velocity plot is depicted and the main events occurring during the flight are shown (e.g., stages burnout and fairing jettisoning).

It is clear that the $4^{\text {th }}$ stage is hardly needed to increase the launcher's velocity. It has a maximum thrust lower than that of the other stages, since the atmospheric influence is much smaller compared to the operational regime of the previous stages: the higher thrust is necessary to escape the gravitational attraction and to overcome the atmospheric effects.

\section{B. Ariane-5 ESC-A}

The second launcher analyzed for this feasibility study and discussed in this paper, is the Ariane-5 launched from Kourou. The Ariane-5 is a two-stage vehicle provided with two boosters. The maximum endurable dynamic pressure is $40000 \mathrm{~Pa}$, while the maximum axial acceleration is 4.55 g. ${ }^{16}$ 


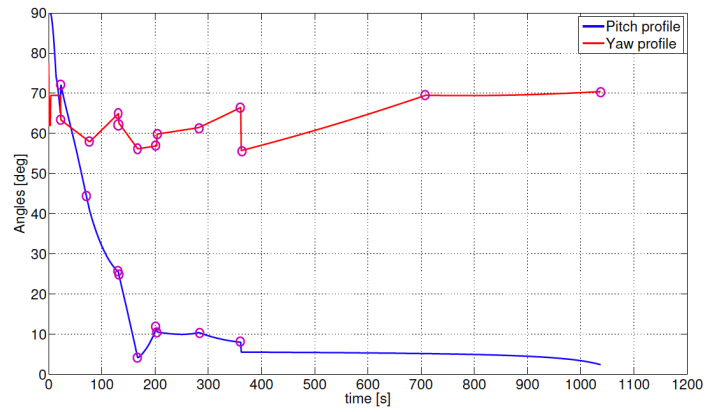

(a) Control history.

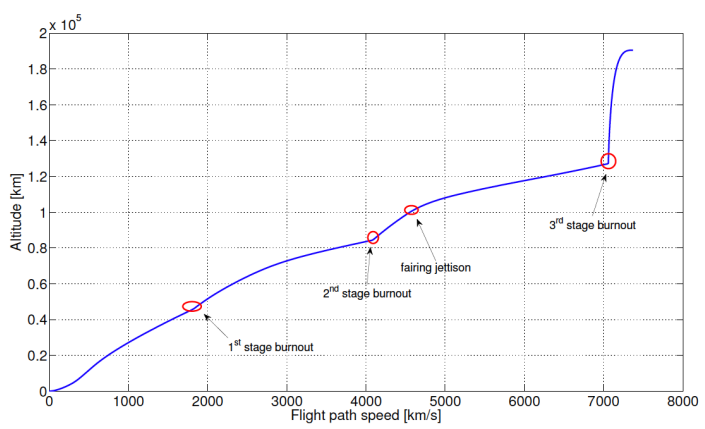

(b) Altitude-velocity profile.

Figure 7. Vega: best solution.

\section{One-objective optimization results}

For the Ariane-5 the input settings are given in Table 7. As Table 8 shows, no violations of peak heat flux, axial acceleration, semimajor axis and inclination (except in one case) occur. Concerning the axial acceleration, this launcher has two solid propellant boosters with a thrust profile tailored not to violate it. Therefore, the option to include the thrust profile for boosters has been implemented and no violations for this constraint occurred.

Between the three aerodynamic configurations, the best one violates the bending-load constraint more often. This is related to the higher velocity, less drag and the fact that possibly non-optimal parameters for the pitch-over phase have been found. These three factors generate high dynamic pressure and high angles of attack that result in bending load violations. The range azimuth is also violated sometimes and mostly in those trajectories with bending load violations.

Concerning the bending load, in run 7, it might be violated also because of the more strict tolerance on the eccentricity. This orbital elements sometimes can be coupled to the bending load constraint as, to reach a better accuracy, usually a less steep trajectory has to be flown. The vehicle, then, spends more time in the denser layers of the atmosphere, with higher chances to violate dynamic pressure and bending load.

On the other hand, run 3 shows that also a more strict bending load constraint may produce errors in the eccentricity.

For all the runs, the payload masses range between 16,890 kg and 24,000 kg. Problems occurred in the simulations as, during the gravity turn flown by the boosters and the first stage, the launcher was first pitching down, then up and then down again, following its reference guidance. For this reason, the number of nodes in the first stage has been reduced to 2 in the runs 4, 6, 8 and 9 . This behaviour may be the result from the combination of high angle of attack, lift and thrust force.

For the Ariane-5, the most critical constraint is the bending load and this is due to the difficulty of the optimizer to find optimal parameters for the control laws that can keep the angles of attack low.

Table 7. Ariane-5: setup of the single-objective optimization runs.

\begin{tabular}{|c|c|c|c|c|c|c|c|c|c|}
\hline Parameter & Simulation 1 & Simulation 2 & Simulation 3 & Simulation 4 & Simulation 5 & Simulation 6 & Simulation 7 & Simulation 8 & Simulation 9 \\
\hline $\mathrm{a}[\mathrm{km}]$ & 6563.137 & 6563.137 & 6563.137 & 6563.137 & 6563.137 & 6563.137 & 6563.137 & 6563.137 & 6563.137 \\
\hline e [-] & 0 & 0 & 0 & 0 & 0 & 0 & 0 & 0 & 0 \\
\hline$i$ [deg] & 5.5 & 5.5 & 5.5 & 5.5 & 5.5 & 5.5 & 5.5 & 5.5 & 5.5 \\
\hline Tolerance a [km] & 3 & 3 & 3 & 3 & 3 & 3 & 3 & 3 & 3 \\
\hline Tolerance e [-] & 0.0005 & 0.0005 & 0.0005 & 0.0005 & 0.0005 & 0.0005 & 0.0001 & 0.0005 & 0.0005 \\
\hline Tolerance i [deg] & 0.1 & 0.1 & 0.1 & 0.1 & 0.1 & 0.1 & 0.1 & 0.1 & 0.1 \\
\hline \begin{tabular}{|l|} 
Dynamic \\
pressure [kPa]
\end{tabular} & $\leq 40$ & $\leq 40$ & $\leq 40$ & $\leq 40$ & $\leq 40$ & $\leq 45$ & $\leq 40$ & $\leq 40$ & $\leq 40$ \\
\hline $\begin{array}{l}\text { Peak heat flux } \\
{\left[\mathrm{kW} / \mathrm{m}^{2}\right]}\end{array}$ & $\leq 120$ & $\leq 100$ & $\leq 100$ & $\leq 100$ & $\leq 100$ & $\leq 100$ & $\leq 100$ & $\leq 120$ & $\leq 100$ \\
\hline \begin{tabular}{|l|} 
Axial \\
acceleration [g]
\end{tabular} & $\leq 4.55$ & $\leq 4.55$ & $\leq 4.55$ & $\leq 4.55$ & $\leq 4.55$ & $\leq 4.55$ & $\leq 4.55$ & $\leq 4.55$ & $\leq 4.55$ \\
\hline $\begin{array}{l}\begin{array}{l}\text { Bending load } \\
\text { [kPa*deg] }\end{array} \\
\end{array}$ & $\leq 300$ & $\leq 150$ & $\leq 100$ & $\leq 120$ & $\leq 100$ & $\leq 120$ & $\leq 150$ & $\leq 150$ & $\leq 150$ \\
\hline \begin{tabular}{|l|}
$\begin{array}{l}\text { Circularization } \\
\text { burn }\end{array}$ \\
\end{tabular} & Yes & Yes & Yes & No & No & No & Yes & No & Yes \\
\hline Coast arcs & No & No & No & No & Yes & Yes & No & No & No \\
\hline
\end{tabular}


Table 8. Ariane-5: results of the single-objective optimizations.

\begin{tabular}{|c|c|c|c|c|c|c|c|c|c|c|c|}
\hline Parameter & & Simulation 1 & Simulation 2 & Simulation 3 & 3 Simulation 4 & Simulation 5 & Simulation 6 & Simulation 7 & Simulation 8 & Simulation 9 & $\mathrm{~W}=$ worst aerodynamic configuration \\
\hline \multirow{3}{*}{ Error a } & w & - & - & - & - & - & - & - & - & - & \multirow{27}{*}{$\begin{array}{l}R=\text { reference aerodynamic configuration } \\
B=\text { best aerodynamic configuration } \\
-=\text { no violation } \\
=\text { = trajectory without path constraint } \\
\text { and orbital element tolerance violations }\end{array}$} \\
\hline & $\mathrm{R}$ & - & - & - & - & - & - & - & - & - & \\
\hline & B & - & - & - & - & - & - & - & - & - & \\
\hline \multirow{3}{*}{ Error e } & W & - & - & 0.00101 & 0.001008 & - & - & 0.000163 & - & 0.001004 & \\
\hline & $\mathrm{R}$ & - & - & - & - & - & - & - & - & - & \\
\hline & B & - & - & - & - & - & - & - & - & - & \\
\hline \multirow{3}{*}{ Error $\mathrm{i}$} & w & - & - & $1.83 \%$ & - & - & - & - & - & - & \\
\hline & $\mathrm{R}$ & - & - & - & - & - & - & - & - & - & \\
\hline & B & - & - & - & - & - & - & - & - & - & \\
\hline \multirow{3}{*}{$\begin{array}{l}\text { Dynamic } \\
\text { pressure } \\
\text { violation [kPa] }\end{array}$} & W & - & - & - & - & - & - & - & - & - & \\
\hline & $\mathrm{R}$ & - & - & 3.7 & - & - & - & - & - & - & \\
\hline & B & - & - & - & - & - & - & 12.7 & 4.4 & - & \\
\hline \multirow{3}{*}{$\begin{array}{l}\text { Peak heat flux } \\
\text { violation } \\
{[\mathrm{kW} / \mathrm{m} 2]}\end{array}$} & W & - & - & - & - & - & - & - & - & - & \\
\hline & $\mathrm{R}$ & - & - & - & - & - & - & - & - & - & \\
\hline & B & - & - & - & - & - & - & - & - & - & \\
\hline \multirow{3}{*}{$\begin{array}{l}\text { Axial } \\
\text { acceleration } \\
\text { violation }[\mathrm{g}]\end{array}$} & W & - & - & - & - & - & - & - & - & - & \\
\hline & $\mathrm{R}$ & - & - & - & - & - & - & - & - & - & \\
\hline & B & - & - & - & - & - & - & - & - & - & \\
\hline \multirow{3}{*}{$\begin{array}{l}\text { Bending load } \\
\text { violation } \\
\text { [kPa*deg] }\end{array}$} & $w$ & 6.7 & - & 198.8 & - & - & - & 225.1 & - & - & \\
\hline & $\mathrm{R}$ & - & - & 260.3 & - & 7.7 & 138.1 & 94.2 & - & - & \\
\hline & $\mathrm{B}$ & 14.6 & 101.6 & 71.5 & 40.3 & 94.9 & - & 346.0 & 249.3 & - & \\
\hline \multirow{3}{*}{$\begin{array}{l}\text { Geographical } \\
\text { violation [deg] }\end{array}$} & W & - & - & - & - & 0.05 & 1 & 1.5 & - & - & \\
\hline & $\mathrm{R}$ & - & 0.8 & - & 0.3 & & 1.5 & 1 & - & - & \\
\hline & B & 0.8 & - & - & - & 0.2 & - & 1.4 & 3 & - & \\
\hline \multirow{3}{*}{$\begin{array}{l}\text { Final payload } \\
\text { mass }[\mathrm{kg}]\end{array}$} & W & 17,367 & 20,144 & 23,321 & 19,365 & 20,228 & 21,143 & 19,855 & 21,296 & 21,691 & \\
\hline & $\mathrm{R}$ & 21,613 & 20,455 & 20,503 & 18,341 & 19,229 & 21,335 & 19,665 & 21,038 & 23,671 & \\
\hline & B & 16,890 & 20,783 & 19,600 & 18,019 & 19,930 & 24,000 & 20,377 & 22,813 & 21,558 & \\
\hline
\end{tabular}

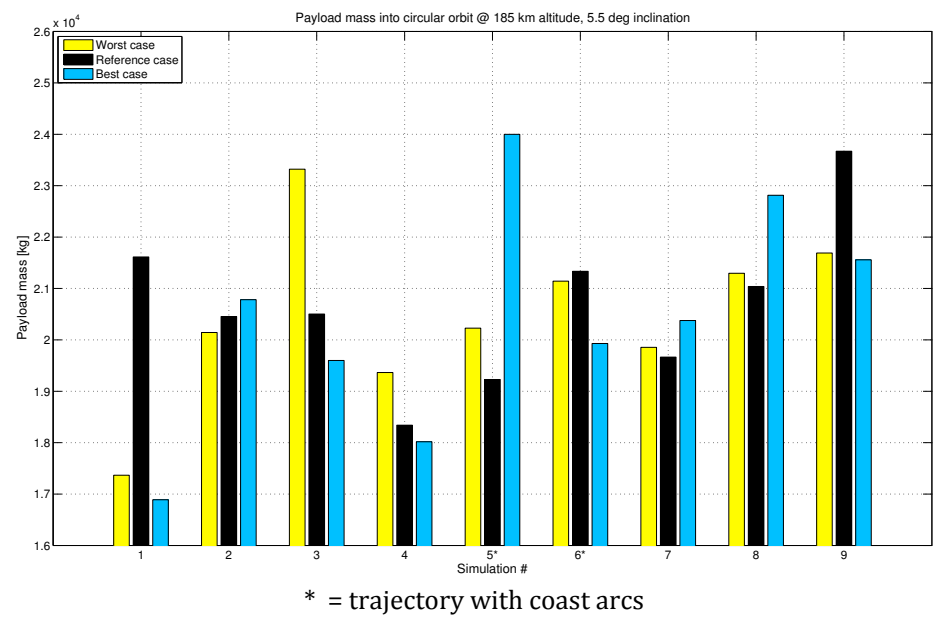

Figure 8. Ariane-5: summary of the payload masses obtained from the one-objective optimization.

\section{Two-objective optimization results}

For the two-objective optimization, 4 runs have been performed for Ariane-5. Two of these runs have the payload mass and the $R S S$ of the orbital elements as objectives while the other two runs have payload mass and $R S S$ of the path constraints.

Concerning the first two runs, from Table 10 it is evident that the reference aerodynamic configuration performs better than the others. In the first run, where the bending load constraint is higher with respect to the second, the reference configuration outperforms the other. As explanation one can think that with the best configuration, the launcher has too high velocity and, in order not to violate the bending load, flies a steeper trajectory with some problems in reaching the set accuracy on the eccentricity. With the worst configuration, the opposite effect might occur: that the launcher experiences high drag and has more difficulties in reaching the final eccentricity. Moreover, about the worst configuration, in run 1, the Pareto front on the left side is not perfectly linear as in the reference configuration. This might mean that the optimization did not fully converge and that, as constrained problem, there might be other feasible solutions that yield higher payload masses at the same level of accuracy. 
The worst configuration, in run 2, has few solutions in the lower part of the front, from which is difficult to understand if other solutions might have a better accuracy. To solve this problem a run should have been performed with a higher number of particles in the initial population. On the other hand, in run 1, it seems that this configuration is not able to achieve an accuracy better than the lower found and this can be seen form the lower part of the front.

From a payload mass point of view, a quite high value is obtained, in the aforementioned run and configuration, equals to $25,420 \mathrm{~kg}$. In run 2 , however, a lower payload mass has been achieved due to the more strict bending load constraint.

For the optimization runs involving the $R S S$ of the path constraints, no solutions without violations have been found. This confirms the results from the single-objective optimization, in which in several runs and configurations, violations occurred, especially in the bending load. And the bending load is the main factor that drives the variety of the Pareto front since in the run where it is more strict a less wide front is found (as shown in Fig. 9(d)).

Table 9. Ariane-5: setup of the two-objective optimization runs.

\begin{tabular}{|l|c|c|c|c|}
\hline Parameter & Simulation 1 & Simulation 2 & Simulation 3 & Simulation 4 \\
\hline $\mathrm{a}[\mathrm{km}]$ & 6563.137 & 6563.137 & 6563.137 & 6563.137 \\
\hline $\mathrm{e}[-]$ & 0 & 0 & 0 & 0 \\
\hline $\mathrm{i}[\mathrm{deg}]$ & 5.5 & 5.5 & 5.5 & 5.5 \\
\hline Tolerance a [km] & 3 & 3 & 3 & 3 \\
\hline Tolerance e [-] & 0.0005 & 0.0005 & 0.0005 & 0.0005 \\
\hline Tolerance i [deg] & 0.1 & 0.1 & 0.1 & 0.1 \\
\hline $\begin{array}{l}\text { Dynamic } \\
\text { pressure [kPa] }\end{array}$ & $\leq 40$ & $\leq 40$ & $\leq 40$ & $\leq 40$ \\
\hline $\begin{array}{l}\text { Peak heat flux } \\
{\left[\mathrm{kW} / \mathrm{m}^{2}\right]}\end{array}$ & $\leq 100$ & $\leq 100$ & $\leq 100$ & $\leq 100$ \\
\hline $\begin{array}{l}\text { Axial acceleration } \\
{[\mathrm{g}]}\end{array}$ & $\leq 4.55$ & $\leq 4.55$ & $\leq 4.55$ & $\leq 4.55$ \\
\hline $\begin{array}{l}\text { Bending load } \\
{[\mathrm{kPa} \text { deg] }}\end{array}$ & $\leq 150$ & $\leq 120$ & $\leq 120$ & $\leq 100$ \\
\hline $\begin{array}{l}\text { Circularization } \\
\text { burn }\end{array}$ & No & Yes & Yes & No \\
\hline Coast arcs & No & Yes & No & No \\
\hline
\end{tabular}

Table 10. Ariane-5: results of the two-objective optimizations.

\begin{tabular}{|c|c|c|c|c|c|c|c|c|}
\hline & \multicolumn{2}{|c|}{ Run 1} & \multicolumn{2}{|c|}{ Run 2} & \multicolumn{2}{|c|}{ Run 3} & \multicolumn{2}{|c|}{ Run 4} \\
\hline & \begin{tabular}{|} 
Payload mass \\
{$[\mathrm{kg}]$}
\end{tabular} & $\begin{array}{c}\text { RSS orbital } \\
\text { elements }\end{array}$ & $\begin{array}{c}\text { Payload mass } \\
{[\mathrm{kg}]}\end{array}$ & $\begin{array}{l}\text { RSS orbital } \\
\text { elements }\end{array}$ & \begin{tabular}{|c|} 
Payload mass \\
{$[\mathrm{kg}]$}
\end{tabular} & $\begin{array}{c}\text { RSS path } \\
\text { constraints }\end{array}$ & $\begin{array}{c}\text { Payload mass } \\
{[\mathrm{kg}]}\end{array}$ & $\begin{array}{c}\text { RSS path } \\
\text { constraints }\end{array}$ \\
\hline \multirow{3}{*}{ Worst } & 20,757 & 6.78 & 20,624 & 5.05 & 19,814 & 0.67 & 18,751 & 35.46 \\
\hline & 20,782 & 6.79 & 20,805 & 5.06 & 19,998 & 0.7 & & \\
\hline & 21,042 & 6.81 & 20,806 & 5.26 & 20,412 & 0.85 & & \\
\hline \multirow{3}{*}{ Reference } & 25,265 & 0.82 & 21,571 & 0.57 & 21,312 & 1.18 & 19,452 & 15.71 \\
\hline & 25,266 & 0.83 & 21,590 & 0.83 & 21,321 & 1.18 & 19,468 & 15.75 \\
\hline & 25,420 & 0.90 & 22,142 & 0.96 & 21,322 & 1 & 19,489 & 15.76 \\
\hline \multirow{3}{*}{ Best } & 21,534 & 1.07 & 23,298 & 2.48 & 22,265 & 2.59 & 21,533 & 1.76 \\
\hline & 21,786 & 1.29 & 23,323 & 2.56 & 22,229 & 2.59 & 21,545 & 1.76 \\
\hline & 21,817 & 1.53 & 23,550 & 2.92 & 22,239 & 2.59 & 21,546 & 1.77 \\
\hline
\end{tabular}

For the worst configuration, in run 4, only one solution has been found. That means no other solutions, with a higher accuracy and a lower payload mass or vice versa, have been found. To avoid this kind of problem, the advice for future work is to have a larger initial population from which more solutions can be found and also a larger search space can be covered. The same holds for the reference configuration, in run 3 , where the front is made up by only 5 solutions.

\section{Three-objective optimization results}

Also for the three-objective optimization, for the Ariane-5, four runs have been performed. Three out of four runs use payload mass, $R S S$ of the path constraints and $R S S$ of the orbital elements as objectives. The fourth run uses payload mass and $R S S$ of two groups of path constraints as objectives. The two groups of constraints, for the fourth run, are made by dynamic pressure and axial acceleration on one side and peak heat flux, bending load and azimuth range on the other.

In Table 12 the solutions have been sorted out first for path constraints violation. Therefore, it is evident that there are, in the first three runs, solutions that do no violate any constraints. Secondly, those solutions were sorted according the lower $R S S$ of the orbital elements. When this criterion is applied, it is clear that 


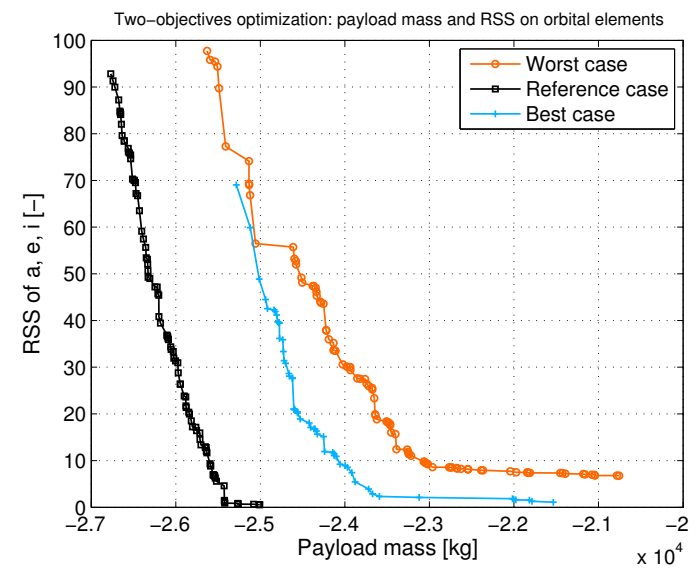

(a) Run 1. The second objective is the RSS of the orbital elements.

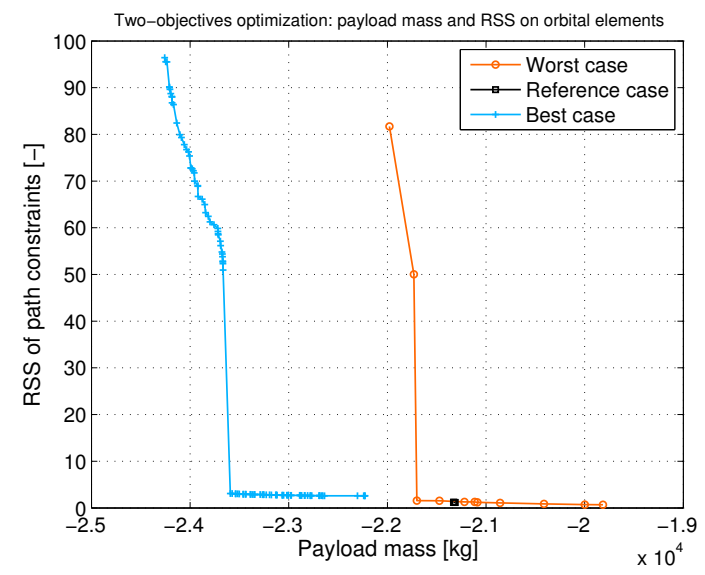

(c) Run 3. The second objective is the RSS of the path constraints.

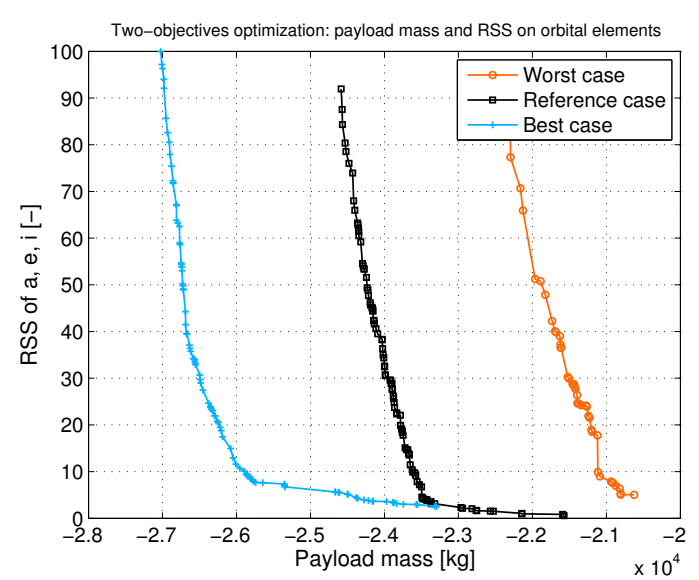

(b) Run 2. The second objective is the $R S S$ of the orbital elements.

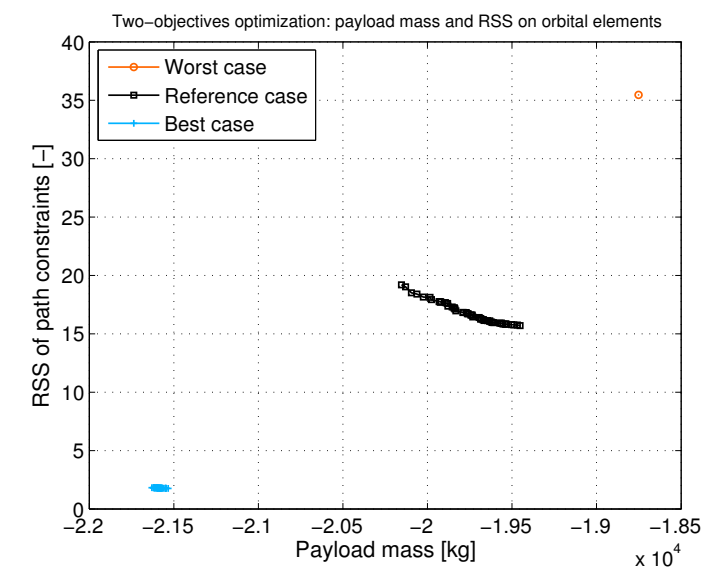

(d) Run 4. The second objective is the RSS of the path constraints.

Figure 9. Ariane-5: Pareto fronts for two-objective optimization results.

all the solutions that do not violate the constraints reach a low accurate orbit. Also in the three-objective optimization, more than in the other two kinds of optimization, it is evident how difficult it is to find a good solution for this launcher. One recommendation is to increase the initial population size together with an angle-of-attack constraint.

The fact that several constraints are violated, and sometimes quite heavily, is shown also in run 4 , from Table 12.

From run 1, the best aerodynamic configuration gives higher payload mass and a better accuracy. A good accuracy is also given by the reference configuration. On the other hand, the worst configuration is more capable of satisfying the constraints but yielding a lower payload mass. Also run 2 presents similar results for the best configuration, however the reference one satisfies the constraints better with respect to the other two. Moreover, for same values of $R S S$ of path constraints, the best configuration gives higher payload.

Different are the results of run 3, where the worst configuration outperforms the other two in payload and accuracy, whereas the best configuration satisfies the constraints better.

By analyzing run 4, it can be said which group of constraints is better satisfied. It results that the best aerodynamic configuration satisfies the dynamic pressure better (since the axial acceleration is controlled by the fact of having a tailored boosters' thrust profile), but also the second group (peak heat flux, bending load and azimuth range). 
Table 11. Ariane-5: setup of the three-objective optimization runs.

\begin{tabular}{|c|c|c|c|c|}
\hline Parameter & Simulation 1 & Simulation 2 & Simulation 3 & Simulation 4 \\
\hline $\mathrm{a}[\mathrm{km}]$ & 6563.137 & 6563.137 & 6563.137 & 6563.137 \\
\hline e $[-]$ & 0 & 0 & 0 & 0 \\
\hline$i$ [deg] & 5.5 & 5.5 & 5.5 & 5.5 \\
\hline \begin{tabular}{|l} 
Tolerance a $[\mathrm{km}]$ \\
\end{tabular} & 3 & 3 & 3 & 3 \\
\hline \begin{tabular}{|l} 
Tolerance e $[-]$ \\
\end{tabular} & 0.0005 & 0.0005 & 0.0005 & 0.0005 \\
\hline \begin{tabular}{|l} 
Tolerance i [deg] \\
\end{tabular} & 0.1 & 0.1 & 0.1 & 0.1 \\
\hline \begin{tabular}{|l} 
Dynamic \\
pressure [kPa]
\end{tabular} & $\leq 40$ & $\leq 40$ & $\leq 40$ & $\leq 40$ \\
\hline $\begin{array}{l}\text { Peak heat flux } \\
{\left[\mathrm{kW} / \mathrm{m}^{2}\right\rceil}\end{array}$ & $\leq 100$ & $\leq 100$ & $\leq 100$ & $\leq 100$ \\
\hline $\begin{array}{l}\text { Axial acceleration } \\
\text { [g] }\end{array}$ & $\leq 4.55$ & $\leq 4.55$ & $\leq 4.55$ & $\leq 4.55$ \\
\hline $\begin{array}{l}\text { Bending load } \\
{[\mathrm{KPa} * \mathrm{deg}]}\end{array}$ & $\leq 150$ & $\leq 120$ & $\leq 120$ & $\leq 100$ \\
\hline $\begin{array}{l}\text { Circularization } \\
\text { burn }\end{array}$ & No & Yes & Yes & No \\
\hline Coast arcs & No & Yes & No & No \\
\hline
\end{tabular}

Table 12. Ariane-5: results of the three-objective optimizations.

\begin{tabular}{|c|c|c|c|c|c|c|c|c|c|c|c|c|}
\hline & \multicolumn{3}{|c|}{ Run 1} & \multicolumn{3}{|c|}{ Run 2} & \multicolumn{3}{|c|}{ Run 3} & \multicolumn{3}{|c|}{ Run 4} \\
\hline & $\begin{array}{c}\text { Payload } \\
\text { mass [kg] }\end{array}$ & $\begin{array}{c}\text { RSS path } \\
\text { constraints }\end{array}$ & $\begin{array}{c}\text { RSS orbital } \\
\text { elements }\end{array}$ & $\begin{array}{c}\text { Payload } \\
\text { mass }[\mathrm{kg}]\end{array}$ & $\begin{array}{c}\text { RSS path } \\
\text { constraints }\end{array}$ & $\begin{array}{c}\text { RSS orbital } \\
\text { elements }\end{array}$ & $\begin{array}{c}\text { Payload } \\
\text { mass }[\mathrm{kg}]\end{array}$ & $\begin{array}{c}\text { RSS path } \\
\text { constraints }\end{array}$ & $\begin{array}{c}\text { RSS orbital } \\
\text { elements }\end{array}$ & $\begin{array}{c}\text { Payload } \\
\text { mass [kg] }\end{array}$ & $\begin{array}{l}\text { RSS path } \\
\text { constraints } \\
\text { (group 1) }\end{array}$ & \begin{tabular}{|c|} 
RSS path \\
constraints \\
(group 2) \\
\end{tabular} \\
\hline \multirow{3}{*}{ Worst } & 19,621 & 0 & 69.17 & 20,616 & 0 & 25.44 & 19,150 & 0 & 2.24 & 23,195 & 37.94 & 5.88 \\
\hline & 20,019 & 0 & 70.84 & 20,756 & 0 & 36.46 & 20,308 & 0 & 4.16 & 23,247 & 37.97 & 5.84 \\
\hline & 21,605 & 0 & 84.9 & 21,318 & 0 & 41.5 & 23,294 & 0 & 13.02 & 23,253 & 38.31 & 5.79 \\
\hline \multirow{3}{*}{ Reference } & 23,685 & 0 & 6.16 & 19,999 & 0 & 12.62 & 21,624 & 0 & 6.51 & 20,740 & 15.91 & 4.42 \\
\hline & 23,791 & 0 & 9.81 & 21,254 & 0 & 15.14 & 22,754 & 0 & 16.4 & 20,739 & 15.95 & 4.41 \\
\hline & 23,903 & 0 & 10.17 & 22,033 & 0 & 15.74 & 23,209 & 0 & 25.74 & 20,735 & 16.2 & 4.36 \\
\hline \multirow{3}{*}{ Best } & 24,406 & 0 & 12.03 & 23,617 & 0 & 13.64 & 23,704 & 0 & 19.34 & 20,244 & 0.11 & 2.2 \\
\hline & 24,406 & 0 & 12.04 & 24,231 & 0 & 13.85 & 23,741 & 0 & 24.34 & 20,283 & 0.11 & 2.21 \\
\hline & 24,413 & 0 & 12.19 & 24,264 & 0 & 15.91 & 23,915 & 0 & 37.42 & 20,263 & 0.11 & 2.21 \\
\hline
\end{tabular}

\section{Conclusions}

With the Ariane-5, it has been highlighted what the effect of not having an angle-of-attack constraint can be on the trajectory. Besides this consideration, the vehicle with the reference aerodynamic configuration yielded the largest payload mass of $25,420 \mathrm{~kg}$, from the two-objective optimization in run 1 .

The circularization burn has not helped to find better solutions and, on average, the runs that do not include it give a slightly higher payload mass.

In Fig. 10(a), the control history for the the best solutions can be observed. It is clear that the gravity turn is quite long as it is flown along all the burning phase of the core stage. When the boosters are thrusting, the altitude and the velocity are almost linearly related. On the other hand, when the boosters are jettisoned, the launcher is still flying a gravity turn that brings the vehicle in a quasi-tangential attitude. However, when the upper stage is started, the launcher increases its altitude and slightly its velocity. In Fig. 10(b) it can be seen that the altitude goes beyond $230 \mathrm{~km}$. Even though this control profile brings the vehicle at a much higher altitude than required, it is still optimum as the gained potential energy is successively converted into kinetic energy to achieve the velocity for the target orbit.

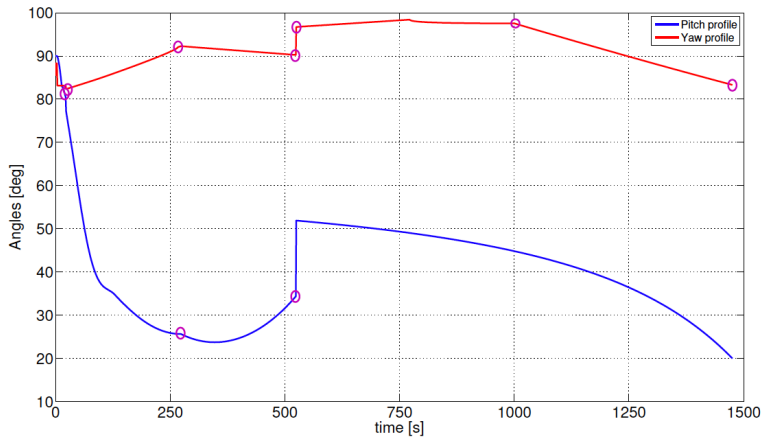

(a) Control history.

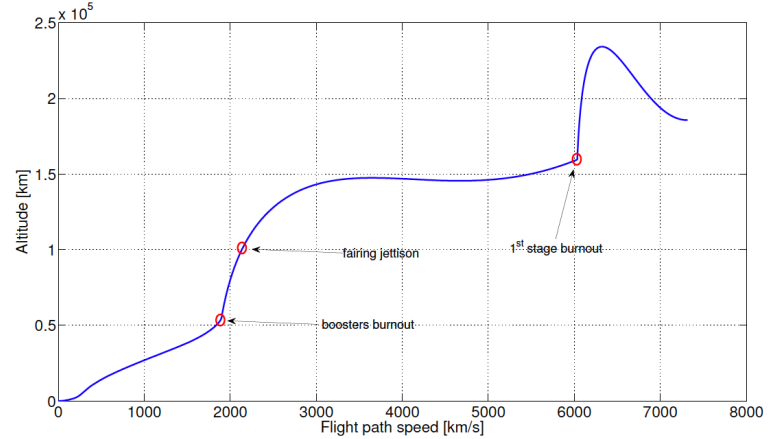

(b) Altitude-velocity profile.

Figure 10. Ariane-5: best solution. 


\section{Other launch vehicles}

For the other launch vehicles, a short overview of the final results is given. The payload masses are summarized by optimization type in Tables 13 and 14. It is evident that Ariane- 5 ESC-A delivers the largest payload mass with 25 tons. The Atlas V 552 and Proton M follow with about 24 and 23 tons.

A particular note has to be mentioned about the Delta IV Heavy and the Atlas V HLV. The preliminary single-objective analysis made for these two launchers showed the deficiency of the software and the particular deficiency to cope with several throttle strategies. Moreover, not much can be said from the results obtained from the optimizations of these two launchers, since the process was not successful.

Table 13. Vega: best payload masses obtained at different orbit inclination. The solutions with an asterisk do not satisfy the path constraints or the orbital elements tolerances.

\begin{tabular}{|c|c|c|c|}
\cline { 2 - 4 } \multicolumn{1}{c|}{} & \multicolumn{3}{c|}{ Vega } \\
\hline $\begin{array}{c}\text { Optimization } \\
\text { type }\end{array}$ & $5.5^{\circ}$ & $28.5^{\circ}$ & $51.6^{\circ}$ \\
\hline 1D optimization & 3,453 & 3,475 & 3,172 \\
\hline 2D optimization & 3,405 & 3,269 & $3,263^{*}$ \\
\hline 3D optimization & 3,046 & $\mathrm{~N} / \mathrm{A}$ & $\mathrm{N} / \mathrm{A}$ \\
\hline
\end{tabular}

Table 14. Best payload masses for the launchers. The solutions with an asterisk do not satisfy the path constraints or the orbital elements tolerances.

\begin{tabular}{|c|c|c|c|}
\hline $\begin{array}{c}\text { Optimization } \\
\text { type }\end{array}$ & Proton M & Atlas V 552 & Ariane 5 ESC-A \\
\hline 1D optimization & 23,091 & 22,993 & 24,000 \\
\hline 2D optimization & 23,005 & 22,726 & 25,420 \\
\hline 3D optimization & $23,073 *$ & 24,141 & $19,150 *$ \\
\hline
\end{tabular}

Table 15. Payload masses available in low lunar orbit relative to Earth-Moon transfer method.

\begin{tabular}{|l|c|c|c|c|}
\hline & $\begin{array}{c}\text { High thrust } \\
\text { transfer LLO } \\
\text { payload mass }\end{array}$ & $\begin{array}{c}\text { Low-thrust } \\
\text { transfer LLO } \\
\text { payload mass } \\
\left(\mathrm{I}_{\mathrm{sp}}=1000 \mathrm{~s}\right)\end{array}$ & $\begin{array}{c}\text { Low-thrust } \\
\text { transfer LLO } \\
\text { payload mass } \\
\left(\mathrm{I}_{\mathrm{sp}}=1500 \mathrm{~s}\right)\end{array}$ & $\begin{array}{c}3 \text { body } \\
\text { transfer LLO } \\
\text { payload mass }\end{array}$ \\
\hline Launcher & {$[\mathrm{kg}]$} & {$[\mathrm{kg}]$} & {$[\mathrm{kg}]$} & {$[\mathrm{kg}]$} \\
\hline Ariane 5 & 8,698 & 17,052 & 19,110 & 8,591 \\
\hline Proton M & 5,027 & 16,406 & 18,386 & 9,885 \\
\hline Atlas V 552 & 9,163 & 17,152 & 19,222 & 9,634 \\
\hline
\end{tabular}

Besides that, including the results obtained in the Earth-Moon transfer analysis, ${ }^{17}$ it was found that for Vega it is more suitable to launch into a parking orbit with an inclination of $28.5^{\circ}$, even though plane-changes maneuvers are needed.

On the other hand, concerning the cargo mission involving the heavy lift launchers, we assume the use of the RD-0126E engine in the upper stage $\left(I_{s p}=472 \mathrm{~s}\right)$ for this Earth-Moon transfer. For the landing, we account for $2000 \mathrm{~m} / \mathrm{s}$ of $\Delta V$ and the use of an engine for the lander with an $I_{s p}=350 \mathrm{~s} \mathrm{(Apollo} \mathrm{lander} \mathrm{engine}$ had $I_{s p}=311 \mathrm{~s}$ ). In such a case, that is by means of a 3-body transfer, the final payload mass on the lunar surface could be between 4 and 5 tons, depending on the launcher. However, in Table 15, the payload mass available in lunar parking polar orbit at $100 \mathrm{~km}$ altitude are given. Of course, using a low-thrust transfer more payload could be brought, but it would take longer. Concerning the landing phase, the assumption about the needed $\Delta V$ can be refined in the analysis of the phase itself, maybe yielding a slightly lower $\Delta V$.

From the obtained results, a schedule of the entire development of the lunar mission will be shown. The entire mission requires a huge effort that cannot be taken by a single space agency, but that has to be shared between the international space community. It is a huge effort in terms of money and capabilities, and the International Space Station experience has demonstrated that international cooperation is the best strategy to reach such a dream. 
The schedule is presented in Table 16: the grouping of the expeditions is made by year and a crew expedition for every two cargo launches is flown in order to assemble the base structure and mount the scientific equipment.

Table 16. Launch schedule for the lunar mission to settle a permanent base on the South Pole of the Moon.

\begin{tabular}{|c|c|c|c|c|}
\hline Launch No. & Year & Cargo/Element(s) & Crew & Mass [ton] \\
\hline 1 & 2015 & $\begin{array}{l}\text { Communication } \\
\text { satellites }\end{array}$ & & \\
\hline 2 & 2015 & $\begin{array}{l}\text { Airlock module } 1 \\
\text { base }\end{array}$ & & 5 \\
\hline 3 & 2015 & $\begin{array}{l}\text { Supporting } \\
\text { structure }+ \text { shell } \\
\text { module } 1 \text { base }\end{array}$ & & 3.7 \\
\hline 4 & 2015 & & $\begin{array}{l}\text { Crew } \\
\text { expedition }\end{array}$ & \\
\hline 5 & 2015 & $\begin{array}{l}\text { Airlock module } 2 \\
\text { base }\end{array}$ & & 5 \\
\hline 6 & 2015 & $\begin{array}{l}\text { Supporting } \\
\text { structure }+ \text { shell } \\
\text { module } 2 \text { base }\end{array}$ & & 3.7 \\
\hline 7 & 2015 & & $\begin{array}{l}\text { Crew } \\
\text { expedition }\end{array}$ & \\
\hline 8 & 2015 & $\begin{array}{l}\begin{array}{l}\text { Airlock module } 3 \\
\text { base }\end{array} \\
\end{array}$ & & 5 \\
\hline 9 & 2015 & $\begin{array}{l}\text { Supporting } \\
\text { structure }+ \text { shell } \\
\text { module } 3 \text { base }\end{array}$ & & 3.7 \\
\hline 10 & 2015 & & $\begin{array}{l}\text { Crew } \\
\text { expedition }\end{array}$ & \\
\hline 11 & 2015 & $\begin{array}{l}\text { Airlock module } 4 \\
\text { base }\end{array}$ & & 5 \\
\hline 12 & 2016 & $\begin{array}{l}\text { Supporting } \\
\text { structure + shell } \\
\text { module 4 base }\end{array}$ & & 3.7 \\
\hline 13 & 2016 & & $\begin{array}{l}\text { Crew } \\
\text { expedition }\end{array}$ & \\
\hline 14 & 2016 & Payload base & & \\
\hline 15 & 2016 & Payload base & & \\
\hline 16 & 2016 & & $\begin{array}{l}\text { Crew } \\
\text { expedition }\end{array}$ & \\
\hline 17 & 2016 & Payload base & & 4 \\
\hline 18 & 2016 & Payload base & & \\
\hline 19 & 2016 & & $\begin{array}{l}\text { Crew } \\
\text { expedition }\end{array}$ & \\
\hline 20 & 2016 & Payload base & & \\
\hline 21 & 2016 & Payload base & & 4 \\
\hline 22 & 2017 & & $\begin{array}{l}\text { Crew } \\
\text { expedition }\end{array}$ & \\
\hline 23 & 2017 & Payload base & & 4 \\
\hline 24 & 2017 & Payload base & & 4 \\
\hline
\end{tabular}

\begin{tabular}{|c|c|c|c|c|}
\hline Launch No. & Year & Cargo/Element(s) & Crew & Mass [ton] \\
\hline 25 & 2017 & & $\begin{array}{l}\text { Crew } \\
\text { expedition }\end{array}$ & \\
\hline 26 & 2017 & $\begin{array}{l}\text { Airlock emergency } \\
\text { module }\end{array}$ & & \\
\hline 27 & 2017 & \begin{tabular}{|l|} 
Supporting \\
structure + shell \\
emergency module
\end{tabular} & & 3.7 \\
\hline 28 & 2017 & & $\begin{array}{l}\text { Crew } \\
\text { expedition }\end{array}$ & \\
\hline 29 & 2017 & $\begin{array}{l}\text { Airlock spaceport } \\
\text { module } 1\end{array}$ & & 5 \\
\hline 30 & 2017 & $\begin{array}{l}\text { Supporting } \\
\text { structure + shell } \\
\text { spaceport module } 1\end{array}$ & & 3.7 \\
\hline 31 & 2017 & & $\begin{array}{l}\text { Crew } \\
\text { expedition }\end{array}$ & \\
\hline 32 & 2017 & $\begin{array}{l}\text { Airlock spaceport } \\
\text { module } 2\end{array}$ & & 5 \\
\hline 33 & 2018 & $\begin{array}{l}\text { Supporting } \\
\text { structure + shell } \\
\text { spaceport module } 2\end{array}$ & & 3.7 \\
\hline 34 & 2018 & & $\begin{array}{l}\text { Crew } \\
\text { expedition }\end{array}$ & \\
\hline 35 & 2018 & $\begin{array}{l}\text { Payload emergency } \\
\text { module }\end{array}$ & & 3 \\
\hline 36 & 2018 & $\begin{array}{l}\text { Payload emergency } \\
\text { module }\end{array}$ & & 3.5 \\
\hline 37 & 2018 & & $\begin{array}{l}\text { Crew } \\
\text { expedition }\end{array}$ & \\
\hline 38 & 2018 & $\begin{array}{l}\text { Payload spaceport } \\
\text { module }\end{array}$ & & 3 \\
\hline 39 & 2018 & $\begin{array}{l}\text { Payload spaceport } \\
\text { module }\end{array}$ & & 3.5 \\
\hline 40 & 2018 & & $\begin{array}{l}\text { Crew } \\
\text { expedition }\end{array}$ & \\
\hline 41 & 2018 & $\begin{array}{l}\text { Payload spaceport } \\
\text { module }\end{array}$ & & 3 \\
\hline 42 & 2018 & $\begin{array}{l}\text { Payload spaceport } \\
\text { module }\end{array}$ & & 3.5 \\
\hline 43 & 2018 & & $\begin{array}{l}\text { Crew } \\
\text { expedition }\end{array}$ & \\
\hline 44 & 2019 & $\begin{array}{l}\text { Unpressurized and } \\
\text { cargo rovers }\end{array}$ & & 0.7 \\
\hline 45 & 2019 & Pressurized rover & & 6 \\
\hline 46 & 2019 & & $\begin{array}{l}\text { Crew } \\
\text { expedition }\end{array}$ & \\
\hline 47 & 2019 & Telescope & & 1.2 \\
\hline 48 & 2019 & & $\begin{array}{l}\text { Crew } \\
\text { expedition }\end{array}$ & \\
\hline
\end{tabular}

Table 17. Schedule for the maintenance phase of the base.

\begin{tabular}{|c|c|c|c|c|}
\hline Launch No. & Year & Cargo/Element(s) & Crew & Mass [ton] \\
\hline 1 & 2020 & & \begin{tabular}{|l|} 
Crew \\
expedition
\end{tabular} & \\
\hline 2 & 2020 & Supply & & 4 \\
\hline 3 & 2020 & & \begin{tabular}{|l|} 
Crew \\
expedition
\end{tabular} & \\
\hline 4 & 2020 & Supply & & 4 \\
\hline 5 & 2020 & Supply & & 4 \\
\hline
\end{tabular}

The first launch, performed by Vega, will be used to put two communication satellites into a Halo orbit around the Lagrangian $L_{2}$ point. For this first launch the total payload mass is 0.8 tons.

Then, the lunar base building phase can start. The modules will be brought directly to the base site, so that these massive structures do not have to be transported over large distances. Therefore, for safety considerations no crew will be present when the lunar-base parts are delivered. So, initially, the base will be delivered and assembled. Then, the emergency and the spaceport modules will be delivered and assembled. The last step of the building phase consists of delivering the rovers and the telescope.

When both the lunar base and the spaceport are completed, the construction phase ends and the operational phase begins. Astronauts will be sent for permanent residence. They will land on the spaceport and travel to the lunar base with the unpressurized rover, over a distance of about $10 \mathrm{~km}$. A pressurized rover is needed for longer expeditions. However, it is uncertain whether this 6-ton rover will be brought to the lunar base. Currently, it has not been designed yet. It is assumed that the lander is capable of staying 180 
to 210 days on the lunar surface, ${ }^{1}$ meaning that the astronauts will be replaced after this period. Moreover, cargo supply of circa 8 tons per year is required. ${ }^{18}$ This cargo consists of water, oxygen, food, nitrogen, etc. The given value does not take into account the mass of equipment that is needed when something on the base needs to be repaired or replaced due to a failure. This mass depends on the particular situation of the failure and will therefore not be taken into account in the normal supply mass. For this reason, another (dedicated) cargo supply of circa 4 tons per year can be assumed to cover this kind of problems.

Since the three analyzed launchers provide payload masses that differ only by one ton from each other, all three launchers could be used. Two of them may be used for cargo launches, while the third one could be used for crew launches. To conclude, the schedule for the maintenance phase is presented in Table 17.

\section{Conclusion and Recommendations}

In this paper, the single and multi-objective optimization of the ascent trajectories of existing heavy-lift launchers and Vega have been performed. As the whole analysis has to fit in a lunar mission framework, a possible launch schedule has been drafted. The mission analysis makes use of a global optimizer based on a Particle Swarm algorithm, to find the highest payload capabilities of the launchers, satisfying the given tolerances and path constraints at the same time.

The analysis has shown the capabilities of three launchers, Ariane-5 ESC-A, Atlas V 552 and Proton M, with the European launcher currently outperforming the others. However, a more detailed analysis shall be performed for Delta IV and Atlas V HLV as the software was not able to cope with the throttle strategy.

Concerning the performance of the optimizers, the DG-MOPSO equals or slightly outperforms the singleobjective optimizer. This performance may be due to the embedded double grid, which spreads the particles also in the least crowded part of the objective space.

This study also shows that a launcher comparable to Ares V is required. By using existing launch vehicles, if on-time delivery of the cargo is an issue, only 4 to 5 tons can be brought. The low-thrust transfer can increase the payload mass, but the use of the Ares V might permit to speed up the building phase of the lunar base. Therefore, an Ares-V (or Saturn-V)-like launcher is highly recommended for such a mission and for future solar-system-exploration missions.

\section{References}

${ }^{1}$ Exploration Systems Architecture Study Team, Final Report, NASA, November 2005.

${ }^{2}$ Chinese Lunar Exploration Program, http://www.clep.org.cn/, 2006-2007.

${ }^{3}$ Kennedy, J., Eberhart, R. C., "Particle Swarm Optimization", Proc. IEEE International Conference on Neural Networks, pp. 1942-1948, 1995.

${ }^{4}$ Castellini, F., "STA ascent module verication and validation document", ESA Technical Report, 2008.

${ }^{5}$ www.astos.de

${ }^{6}$ Vukelich, S. R., Stoy, S. L., Burns, K. A., Castillo, J. A., Moore, M. E., "Missile DATCOM, Volume 1 - Final Report". McDonnel Douglas Missile Systems Company, December 1988.

${ }^{7}$ Well, K. H., "Neighboring Vehicle Design for a Two-Stage Launch Vehicle", Advanced Design Problems in Aerospace Engineering, Edited by A. Miele and A. Frediani. Kluwer Academic/Plenum Publishers, 2003.

${ }^{8}$ COESA, "U.S. Standard Atmosphere", TM-X 74335, NASA, 1976.

${ }^{9}$ Shi, Y., Eberhart, R. C., "Modified particle swarm optimizer", The 1998 IEEE International Conference on Evolutionary Computation, 1998.

${ }^{10}$ Eberhart, R. C., Shi, Y., "Comparing inertia weight and constriction factors in particle swarm optimization", Evolutionary Computation, 2000.

${ }^{11}$ Castellini, F., "Global optimization techniques in space mission design", Master thesis, Politecnico di Milano, 2008.

${ }^{12}$ Coello Coello, C. A., Toscano Pulido, G., Lechuga, M. S., "Handling multiple objectives with particle swarm optimization", Evolutionary Computation, 2004.

${ }^{13}$ Knowles, J. D., Corne, D. W., "The pareto archived evolution strategy: A new baseline algorithm for multi-objective optimisation", Proceedings of the 1999 Congress on Evolutionary Computation, 1999.

${ }^{14}$ Knowles, J. D., Corne, D. W., "Approximating the non-dominated front using the pareto archived evolution strategy", Evolutionary Computation, 2000.

${ }^{15}$ Hamera K., Mosher T., Gefreh M., Paul R., Slavkin L., Trojan J., "An evolvable lunar communication and navigation constellation architecture", Aerospace Conference, 2008 IEEE, 2008.

${ }^{16}$ Arianespace, "Ariane-5 Users manual", Issue 5, revision 0, 2008.

${ }^{17}$ Zuccarelli, V., "Earth-moon transfer orbits", Master thesis, Delft University of Technology, 2009.

${ }^{18}$ Baker, J. D., Eichstadt, F., "Commercial cargo transport service for ISS", Acta Astronautica, 2005. 